Research Article

\title{
Compression Performance of Newly Designed Replaceable Tubular Steel Piers
}

\author{
Haifeng Li $\mathbb{D}^{1,2}$ Xuehang Zhao, ${ }^{1}$ Wei Sun, ${ }^{1}$ and Zhe Xiong ${ }^{3}$ \\ ${ }^{1}$ College of Civil Engineering, Huaqiao University, Xiamen 361021, China \\ ${ }^{2}$ Key Laboratory for Intelligent Infrastructure and Monitoring of Fujian Province, Huaqiao University, Xiamen 361021, China \\ ${ }^{3}$ School of Civil and Transportation Engineering, Guangdong University of Technology, Guangzhou 510006, China
}

Correspondence should be addressed to Haifeng Li; lihai_feng@126.com

Received 24 February 2020; Revised 14 May 2020; Accepted 1 June 2020; Published 22 June 2020

Academic Editor: Guoqiang Xie

Copyright (C) 2020 Haifeng Li et al. This is an open access article distributed under the Creative Commons Attribution License, which permits unrestricted use, distribution, and reproduction in any medium, provided the original work is properly cited.

To rapidly restore the seismic behaviour of a portal steel bridge column after an earthquake, the installation of replaceable tubular steel piers at the root of a portal steel bridge column is proposed herein. In this study, various tubular steel piers with different structural measures were designed; an axial compression test and a numerical simulation of the newly designed tubular steel piers were performed. The effects of parameters such as the structure of stiffening rib, the strength of LYP steel plate, the size of lowyield-point (LYP) steel plate, and the size of outer constrained steel plate were discussed. The results indicate that local buckling of steel tubular plates is likely to occur at the upper or lower end of those specimens, which belong to type II-A specimens with stiffened LYP steel tubular plates or type III-A specimens with T-shaped LYP steel plates, respectively. This led to the LYP steel plate cannot fully display its function. For type III-B and III-C specimens with embedded LYP steel plates and constrained steel plates on both sides, when the outer steel tubular plates buckle, the internally constrained LYP steel plates provide support for the outer steel tubular plates. The plastic deformation of the specimens is sufficient, and the deformation performance is good. For type IV-A specimens with LYP steel tubular plates and constrained steel plates on both sides, the mechanical behaviour of the new tubular steel piers is significantly improved, and increasing the height of the constrained LYP steel tubular plate can improve the compressive behaviour of the new tubular steel pier. Considering the effect of the steel plate thickness on bearing capacity and deformation performance, the thickness $t_{\mathrm{w}}$ of the outer constrained steel plate should be equal to the thickness $t$ of the common steel tubular plate, and the thickness $t_{\mathrm{f}}$ of the LYP steel tubular plate should satisfy $t \leq t_{\mathrm{f}} \leq 2 t$. Finally, a design formula is proposed to calculate the axial bearing capacity of newly designed tubular steel piers with constrained LYP steel plates.

\section{Introduction}

Rapid urbanisation necessitates the widespread application of novel construction techniques such as tubular steel bridge columns in urban viaduct projects. However, after major earthquakes, the roots of such tubular steel bridge columns are prone to local buckling failure [1]. As an important part of the lifeline project in urban public traffic systems, urban viaducts are highly important for repairs and reconstructions after earthquakes. For an urban viaduct, the lower bridge pier structure controls the seismic performance of the entire bridge project. The bridge pier is the primary component that ensures the safety of the entire bridge project. Several studies have been performed worldwide regarding seismic strengthening methods that are applicable to bridge pier structures. A new generation of low-damage and recoverable bridge pier structures has been emphasised in bridge engineering research. El-Bahey and Bruneau [2, 3] proposed the concept of providing structural fuses between double-column piers, which can be replaced easily to quickly regain the function of double-column piers after earthquakes. El-Bahey et al. performed a pseudostatic test and numerical analysis on these new double-column piers and discussed their seismic performance and mechanical mechanism. Kitada et al. [4] proposed a method for setting an energy consumption zone at a specific position of a steel bridge column and conducted a pseudostatic test. Chen and Chen [5] proposed a method for installing a plastic energy 
dissipation zone on a steel bridge column that can consume plastic energy at a preselected position by adjusting the arrangement of stiffeners on the steel bridge column. Susantha et al. [6] attempted to use LYP steel in the root tubular plates of steel bridge piers and conducted a pseudostatic test to investigate a method for improving the ductility of steel bridge columns with LYP steel plates. Rahmzadeh et al. [7] performed a finite element analysis of newly designed steel bridge columns equipped with steel bars for dissipating plastic energy. Jiang et al. [8,9] proposed a new type of prefabricated joint with replaceable energy-consuming components to quickly repair a structure after earthquakes. In order to achieve the rapid repair of the mechanical performance of portal steel bridge column after earthquakes, Li et al. [10-12] proposed the installation of a replaceable steel pier at root of portal steel bridge column, and some new box steel columns were tested and numerically analysed.

A large number of experimental studies and numerical analyses have been performed by scholars worldwide regarding the mechanical performance of tubular steel piers. Ishizawa and Iura [13] performed a numerical analysis of the static and dynamic performances of a tubular steel bridge column and established a one-dimensional model. AlKaseasbeh and Mamaghani [14] selected thin-walled steel tubular columns with uniform and graded thicknesses as study objects and conducted a numerical analysis to study the mechanical behaviour of the new steel tubular columns under cyclic loading. Chen et al. [15] discussed the effects of local buckling on the mechanical performance of steel bridge columns. Additionally, they proposed a hysteretic model for steel bridge columns. Gao and Usami et al. [16-18] conducted a numerical analysis to study the hysteretic behaviour of an eccentrically compressed tubular steel bridge column. Wang and Toshitaka [19] selected stiffened steel tubular bridge columns as study objects and discussed their mechanical behaviour. Li et al. [20] considered normal-strength and high-strength reinforced concrete (RC) columns as research objects and performed an axial compression test on RC columns. Wang et al. [21] discussed the results of an axial compression test performed on concrete-filled aluminium tubular stub columns. Aslani et al. [22] performed axial compression tests on hollow and concrete-filled spiral welded steel tube columns. Wang et al. [23] selected concrete-filled steel columns as study objects and performed axial compression tests on them. Li et al. [24] performed a numerical analysis to study the mechanical behaviour of concrete-filled stainless steel tubular columns under an axial compression. $\mathrm{Li}$ and Cai [25] established finite element models to investigate the compression performance of concrete-filled double-skin steel tubular stub columns. Zheng and Tao [26] developed numerical models for concrete-filled double-tube columns and discussed their compressive strength and stiffness. Liao et al. [27] tested the axial compression strength of sea sand concrete-filled stainless steel tube stub columns. Huang et al. [28] established numerical models for slender concrete-filled steel tubular columns and investigated their dynamic stability using general boundary conditions. Yan et al. [29] discussed the strength and stiffness of circular tubed steel columns subjected to eccentric compression both experimentally and numerically. Wei et al. [30] tested the hysteretic performance of a shear thickening fluid damper and analysed its energy dissipation capacity. Shi et al. [31] tested 24 welded circular tubes made of high-strength steel under axial compression loading. Xiong et al. [32] performed an experimental study to investigate the dynamic performance of a new doubleskin tubular column under cyclic axial compression loading. He et al. [33, 34] experimentally investigated and discussed the axial compression behaviours of circular and square steel tubular stub columns. Zhou et al. [35] established a finite element model to predict the fire response of CTSRC stub columns and proposed simplified methods to predict the temperatures and load capacities of CTSRC stub columns in fire. Deng et al. [36] performed a pseudostatic test on the repaired predamaged circular bridge piers and evaluated the confinement effectiveness of the different repair materials and techniques. Zhang et al. [37] conducted an axial compression test on double-skin tubular columns (DSTCs) and proposed a simple stress-strain model which can provide reasonably accurate but conservative predictions. The current research indicates that the RC columns with a higher slenderness ratio, a lower reinforcement ratio, and a higher concrete strength grade present a stronger size effect, and their mechanical properties can be similarly affected. The high-strength steel outer tube can provide effective confinement to the concrete, which strengthened the load carrying capacity of concrete-filled steel tubular (CFST) columns. The corresponding simplified model and empirical formulas of CFST columns can effectively predict their mechanical properties.

In this study, replaceable tubular steel piers installed at the root (Figure 1) are regarded as research objects, and various tubular steel piers of different structural measures were designed. The new tubular steel pier was designed such that, after small and medium earthquakes, the plastic deformation of the tubular steel pier was primarily concentrated on the low-yield-point (LYP) steel plates. According to the "GB/T 28905-2012: Low Yield Strength Plates for Construction" [38], LYP steel plates mean the steel plates with lower yielding strength, and the yield strength is less than $235 \mathrm{MPa}$. Therefore, only the LYP steel plates need to be replaced to restore the mechanical performance of the tubular steel pier. After rare earthquakes, however, the LYP steel plates and other components can improve the ultimate deformation capacity of the tubular steel pier. In addition, the entire new tubular steel pier can be replaced to realise the quick repair of portal steel bridge columns after earthquakes. Because the bottom of the portal steel bridge column can be semirigid or hinged, the replaceable tubular steel pier is primarily susceptible to the compression failure mode. Axial compression failure easily occurs to the root of steel piers; hence, the research on the compression behaviour of the tubular steel pier is significant for seismic analysis and design. Systematic study aimed at compression performance of the steel bridge piers is relatively rare, especially the research on energy dissipation capacity under axial compression. Therefore, a compression test and a numerical analysis of the newly designed tubular steel pier were 


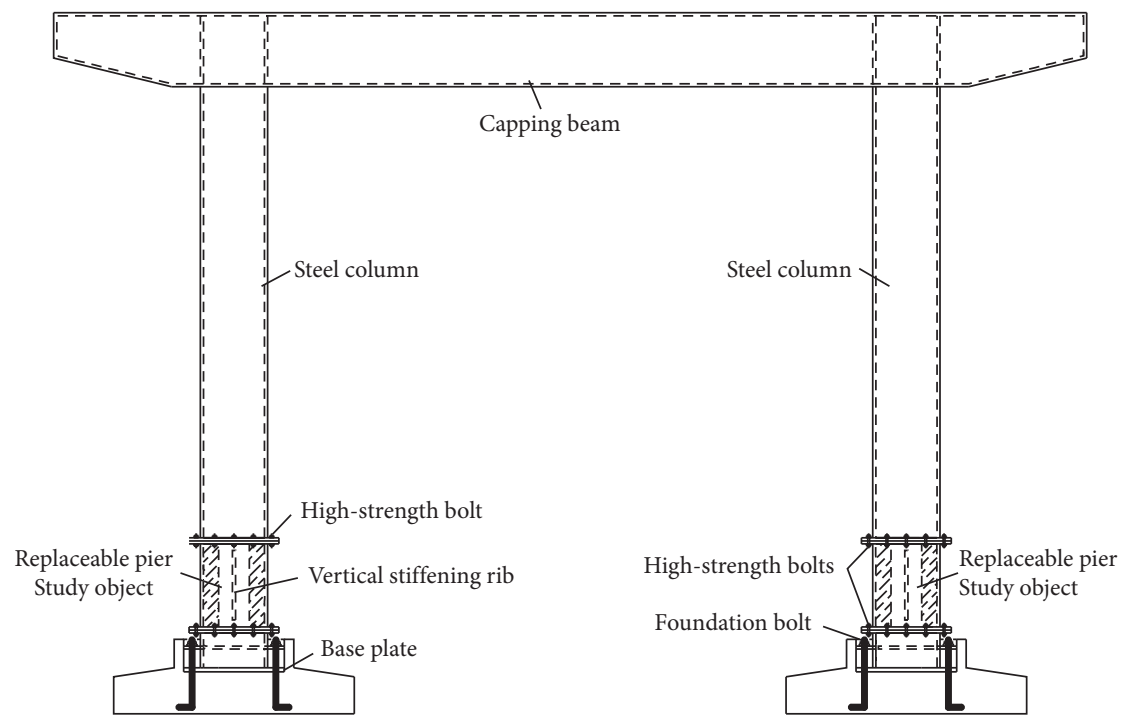

Figure 1: New type of portal steel bridge column with replaceable steel piers.

performed in this study. The following were performed in this study. (a) Axial compression tests of 14 new tubular steel piers were performed, and the failure modes, load-displacement curves, displacement ductility coefficients, and bearing capacity of the specimens were analysed. The effect of different structural details on the mechanical behaviour of the tubular steel pier was discussed. (b) Finite element models of the newly designed tubular steel piers were established and verified using the results of axially compressed tests. Based on the results, a parametric analysis of the full-scale specimen of the new tubular steel pier was performed. (c) Based on the results of test data and numerical simulations, a design formula for the axial bearing capacity of the newly designed tubular steel piers was proposed.

\section{Experimental Investigation}

2.1. Specimen Design. For investigating the effects of different structural details on the axial compression performance of the new tubular steel pier, four sets of 14 axially compressed tubular steel piers were designed. The first group of specimens contained two comparative specimens, I-0 and I-A. Specimen I-0 was a tubular steel pier without any structural measures. Specimen I-A was a tubular steel pier with only vertical stiffeners. The second group of specimens was composed of the newly designed tubular steel pier with LYP steel tubular plates on which stiffeners were provided. According to the form of stiffeners on the LYP steel tubular plates, this group was further subdivided into specimen IIA-1 with +-shaped stiffeners, specimen II-A-2 with $\neq$ shaped stiffeners, and specimen II-A-3 with \#-shaped stiffeners. The third group of specimens was subdivided into three types of the new tubular steel piers denoted as III-A, III-B, and III-C. The type III-A specimens were tubular steel piers with T-shaped LYP steel plates inside. The type III-B and III-C specimens were equipped with embedded LYP steel plates and constrained steel plates on both sides. The constrained steel plates of the III-C specimens were connected with high-strength bolts on the tubular wall plates, while the remaining structural measures were the same as those of the III-B specimens. Some steel tubular plates of the specimens in group IV were made of LYP steel, and both sides of the LYP steel plate were provided with additional constrained steel plates. Group IV comprised three specimens, each of which had a different height $h$ of the LYP steel tubular plates. The material of the tubular plate of specimens was Q345 steel. The material of the energy-consuming steel plates was LYP steel LYP100 or LYP160. The thickness of the stiffeners on the steel tubular plates was $8 \mathrm{~mm}$, the width $50 \mathrm{~mm}$, and the material Q345 steel. The thickness and width of the transverse stiffeners on the energy-consuming steel plates were 8 and $50 \mathrm{~mm}$, respectively. The material was the same as that of the energy-consuming steel plates, which was LYP100 steel or LYP160 steel. High-strength bolts M16 of level 10.9 were used. The design drawing of the new tubular steel piers is shown in Figure 2.

Table 1 shows the design parameters of axially compressed specimens. In Table $1, f$ is the theoretical yield strength of LYP steel plate, DS is the spacing of vertical stiffeners on common steel tubular plate, $H$ is the height of tubular steel pier, $D$ is the outer diameter of tubular steel pier, and $t$ is the thickness of steel tubular plate, $t_{\mathrm{f}}$ is the thickness of LYP steel plate, and $h$ is the height of LYP steel plate.

2.2. Test Setup. In this study, axial compression tests were performed in the structural laboratory of the School of Civil Engineering of Huaqiao University (Xiamen, China). The loading equipment was a 1000-ton electrohydraulic servo multifunction testing machine (Jinan Popwil Instrument Co., Ltd., Jinan, China). The multifunction testing machine can perform vertical bearing capacity test, compressive elastic modulus test, ultimate resistance test, etc. The testing machine adopts microcomputer control to coordinate 


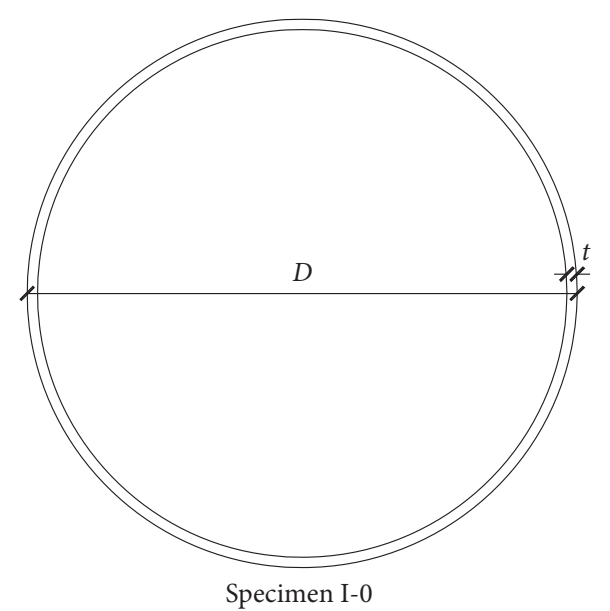

(a)

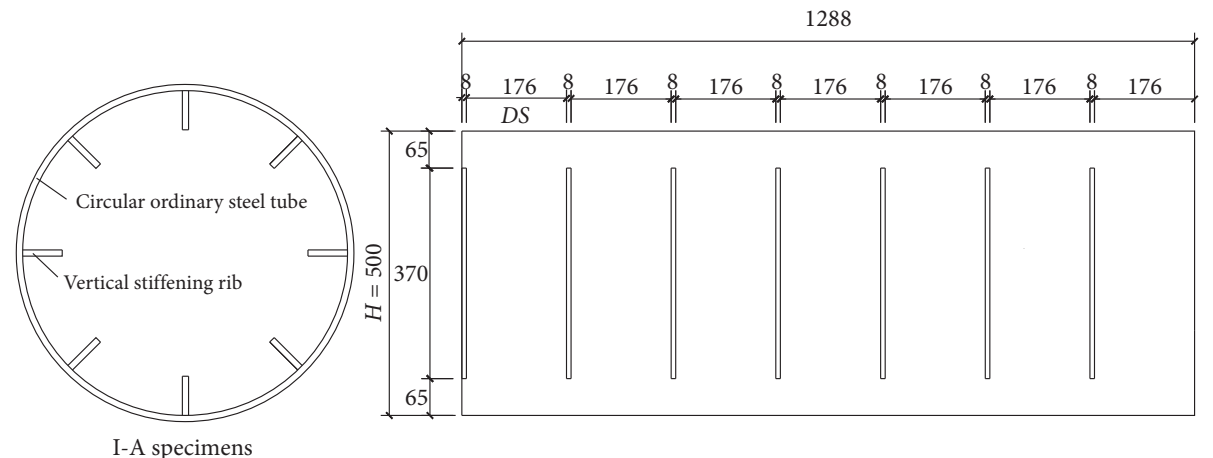

(b)

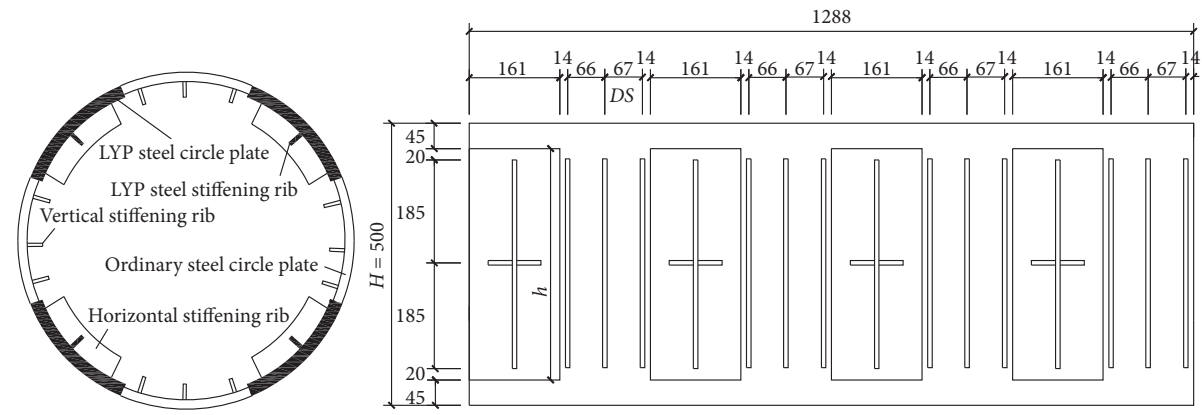

II-A specimens

(c)

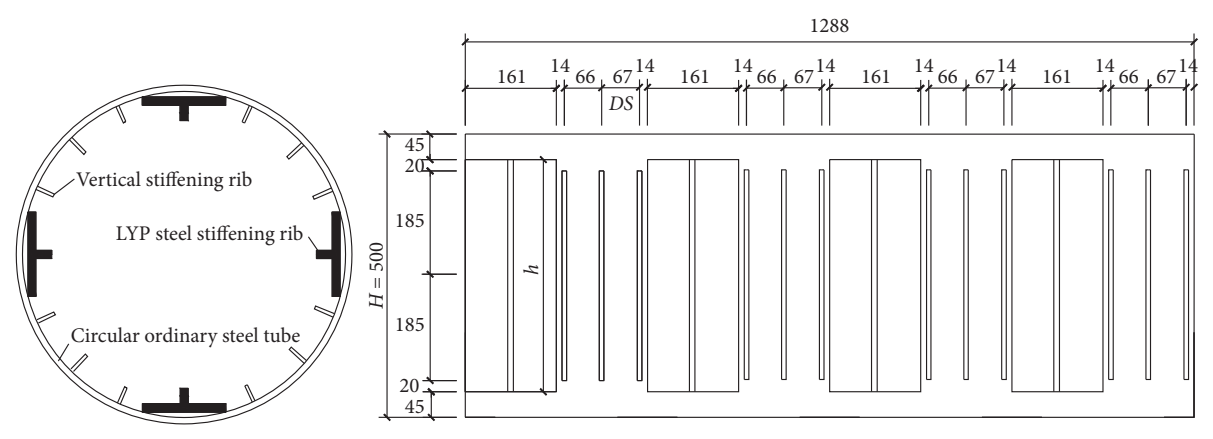

III-A specimens

(d)

Figure 2: Continued. 


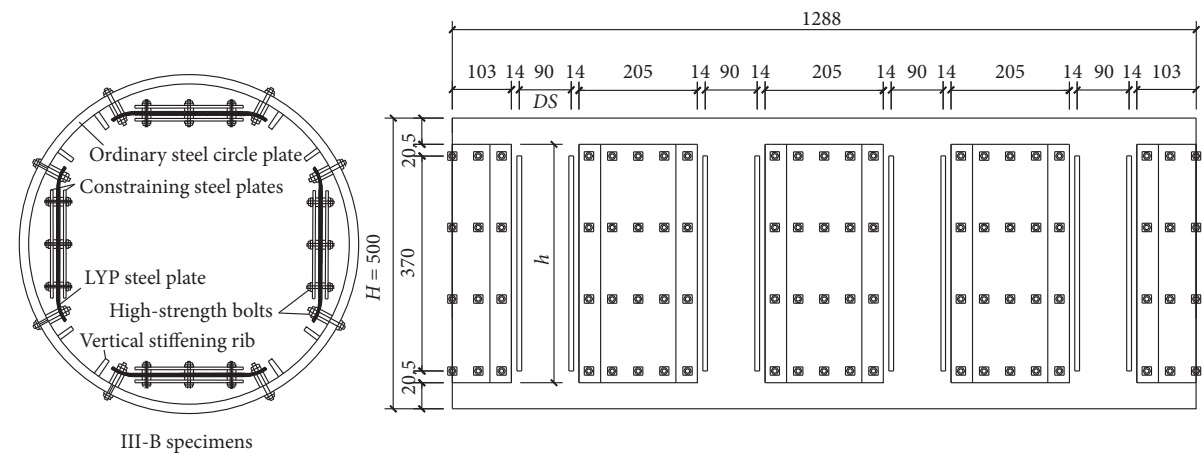

(e)

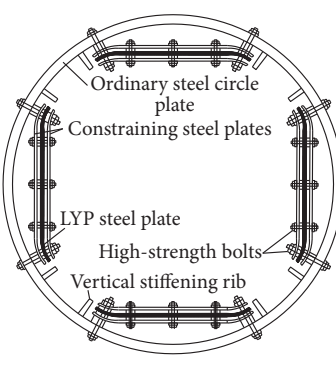

III-C specimens

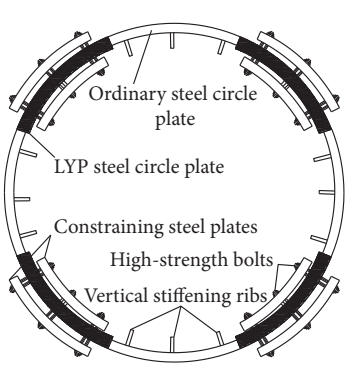

IV-A specimens

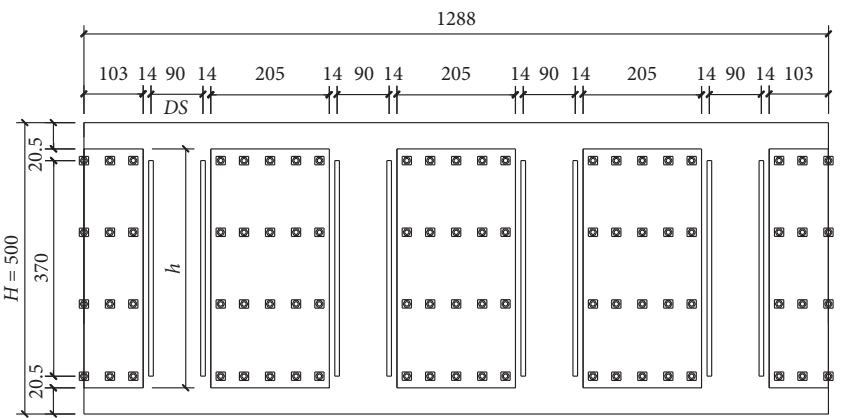

(f)

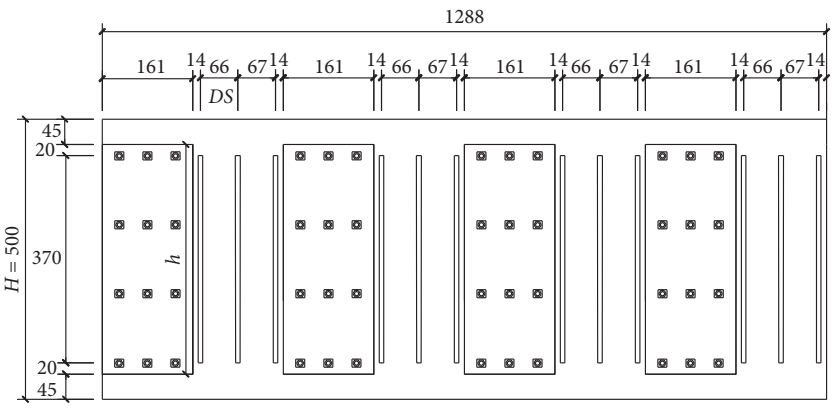

(g)

Figure 2: Design drawings of new replaceable tubular steel piers (units: mm). (a) Cross section of specimen I-0. (b) Cross section and expanded view of type I-A specimens. (c) Cross section and expanded view of type II-A specimens. (d) Cross section and expanded view of type III-A specimens. (e) Cross section and expanded view of type III-B specimens. (f) Cross section and expanded view of type III-C specimens. (g) Cross section and expanded view of type IV-A specimens.

TABLE 1: The design parameters of axially compressed specimens.

\begin{tabular}{|c|c|c|c|c|c|c|c|}
\hline Specimen label & $f(\mathrm{MPa})$ & $D S(\mathrm{~mm})$ & $H(\mathrm{~mm})$ & $D(\mathrm{~mm})$ & $t(\mathrm{~mm})$ & $t_{\mathrm{f}}(\mathrm{mm})$ & $h(\mathrm{~mm})$ \\
\hline $\mathrm{I}-0$ & - & - & 500 & 426 & 8 & - & - \\
\hline I-A & - & 176 & 500 & 426 & 8 & - & - \\
\hline II-A-1 & 160 & 67 & 500 & 426 & 8 & 10 & 410 \\
\hline II-A-2 & 160 & 67 & 500 & 426 & 8 & 10 & 410 \\
\hline II-A-3 & 160 & 67 & 500 & 426 & 8 & 10 & 410 \\
\hline III-A-1 & 100 & 67 & 500 & 426 & 8 & 10 & 410 \\
\hline III-A-2 & 160 & 67 & 500 & 426 & 8 & 10 & 410 \\
\hline III-B-1 & 100 & 90 & 500 & 426 & 8 & 10 & 410 \\
\hline III-B-2 & 160 & 90 & 500 & 426 & 8 & 10 & 410 \\
\hline III-C-1 & 100 & 90 & 500 & 426 & 8 & 10 & 410 \\
\hline III-C-2 & 160 & 90 & 500 & 426 & 8 & 10 & 410 \\
\hline IV-A-1 & 160 & 67 & 500 & 426 & 8 & 10 & 410 \\
\hline IV-A-2 & 160 & 67 & 500 & 426 & 8 & 10 & 350 \\
\hline IV-A-3 & 160 & 67 & 500 & 426 & 8 & 10 & 290 \\
\hline
\end{tabular}


multistage hydraulic loading, automatic acquisition and storage of data, computer control of test progress, and displaying test force and test curve. The axial compression test comprised two stages: preloading and formal loading. The preloading had two levels, of which the load at each level was $5 \%$ and $10 \%$ of the theoretical ultimate load. The formal loading was first controlled by force loading. The load was divided into 4 levels as $20 \%, 40 \%, 60 \%$, and $80 \%$ of the theoretical ultimate load; the loading speed was 2 minutes per level. Subsequently, displacement loading control was induced. When the vertical loading declined to $60 \%$ of the ultimate loading, the test was terminated. The axial compression test loading is illustrated in Figure 3.

2.3. Material Properties. The axial compression specimens involved four types of steel plates, which were Q345 steel plates of thicknesses 14 and $8 \mathrm{~mm}$, a LYP100 steel plate of thickness $10 \mathrm{~mm}$, and LYP160 steel plates of thickness $10 \mathrm{~mm}$. Three specimens were produced for each type of steel plate, and the dimensions of the specimens are shown in Figure 4. The loading process was controlled by the displacement, and the loading speed was $0.8 \mathrm{~mm} / \mathrm{min}$. The loading instrument of the material test is shown in Figure 5 (MTS Systems (China) Co., Ltd., Shenzhen, China). Photographs before and after a tensile test was performed on the material specimens are shown in Figure 6. Table 2 summarises the material test results, including the plate thickness, yield strength, tensile strength, and elongation after the fracture of the specimens.

\section{Test Results and Discussion}

3.1. Experimental Phenomenon. The failure modes of the new tubular steel piers after the axial compression test was performed are shown in Figure 7. As shown, after the LYP steel plates were provided, both the buckling deformation of the tubular steel piers and the deformation ability of the specimens improved. Three main failure modes were associated with the tubular steel piers: (I) local buckling of the LYP steel plates and steel tubular plates at the top of the specimens. The damage was primarily due to plastic deformation, and the buckling deformation at the root of the specimens was not obvious. (II) Local buckling of the LYP steel plates and steel tubular plates at the bottom of the specimens. The damage was also primarily due to plastic deformation, and the buckling deformation at the top of the specimens was not obvious. (III) Concave and convex buckling deformation occurring at the top, middle, and bottom of the specimens, forming undulating buckling deformation. The failure modes of specimens I-A, II-A-1, III-A-2, and IV-A-1 belong to type I; that of II-A-2, II-A-3, III-A-1, IV-A-2, and IV-A-3 to type II; and that of I-0, III-B1, III-B-2, III-C-1, and III-C-2 to type III. Compared with specimens I-0, the specimens with LYP steel plates showed more obvious deformation. This indicates that the LYP steel plate can significantly increase the deformation ability of the tubular steel pier. The specimens III-B and III-C give a better

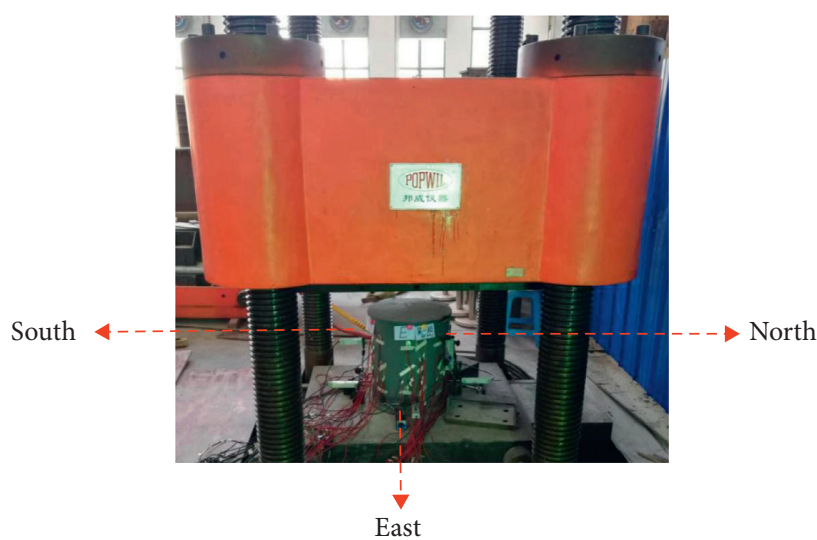

FIgURE 3: Loading system of the axial compression test.

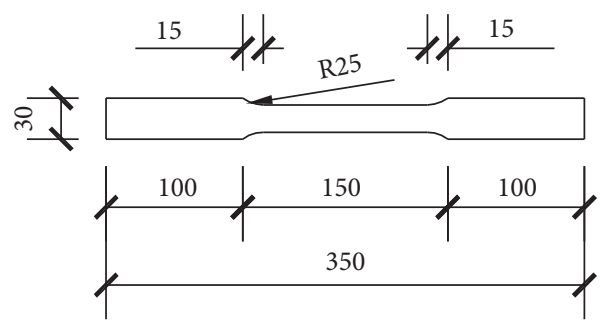

FIGURE 4: Design of the material specimen (units: $\mathrm{mm}$ ).

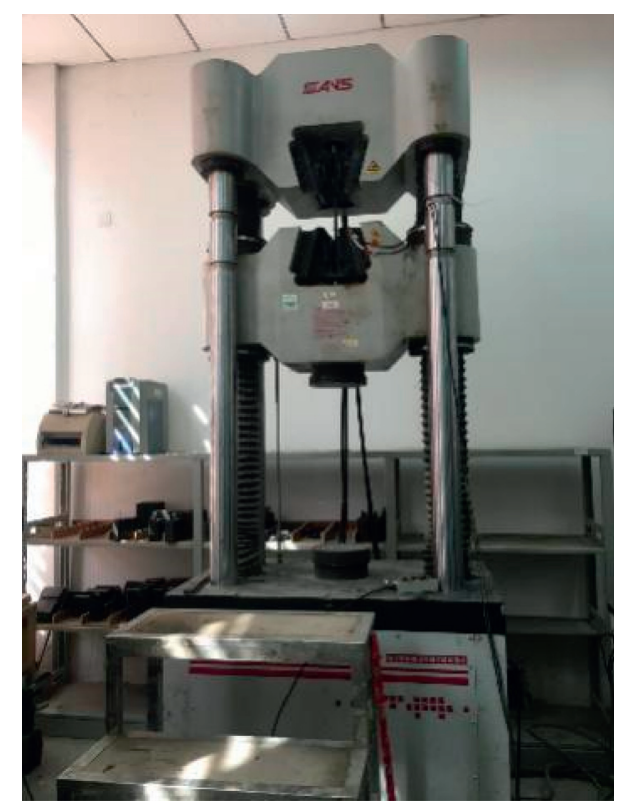

FIgURE 5: Loading instrument for the material test.

performance in terms of failure modes; this indicates that deformation properties of specimens can be most effectively enhanced by the joint action of embedded LYP steel plates and constrained steel plates on both sides.

3.2. Comparison of Load-Displacement Curves. For discussing the effects of various influencing factors on the mechanical 


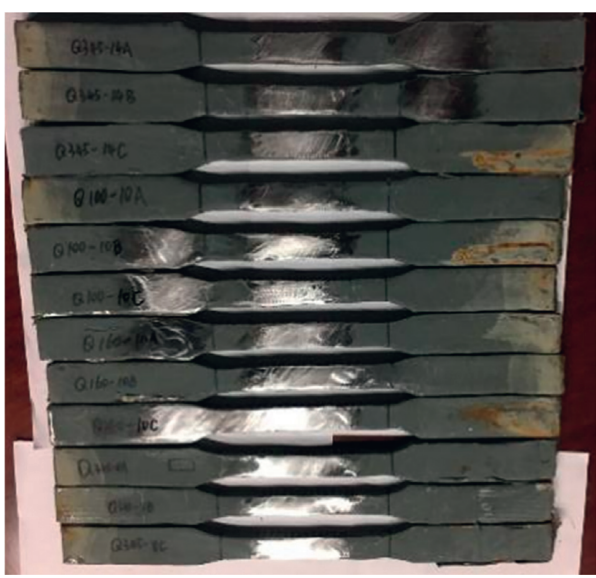

(a)

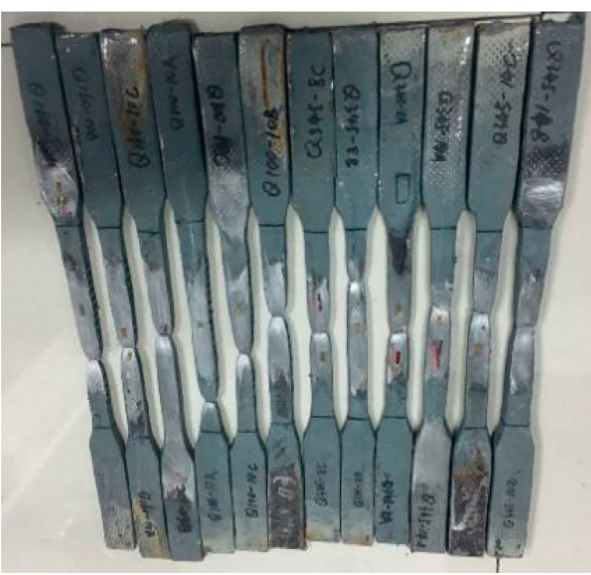

(b)

Figure 6: Photographs of the material specimens. (a) Before stretching. (b) After fracture.

TABLE 2: Test results of steel material specimens.

\begin{tabular}{|c|c|c|c|c|c|}
\hline \multicolumn{2}{|c|}{ Label of material specimens } & \multirow{2}{*}{$\begin{array}{c}\text { Thickness }(\mathrm{mm}) \\
8.0\end{array}$} & \multirow{2}{*}{$\begin{array}{c}\text { Yield strength }(\mathrm{MPa}) \\
323\end{array}$} & \multirow{2}{*}{$\begin{array}{c}\text { Tensile strength }(\mathrm{MPa}) \\
408\end{array}$} & \multirow{2}{*}{$\begin{array}{c}\text { Rate of elongation (\%) } \\
14.5\end{array}$} \\
\hline \multirow{5}{*}{$8 \mathrm{~mm}$} & Q345-1 & & & & \\
\hline & Q345-2 & 7.7 & 357 & 448 & 17.3 \\
\hline & Q345-3 & 7.7 & 355 & 453 & 15.3 \\
\hline & Average & 7.8 & 345 & 436 & 15.7 \\
\hline & Standard deviation & 0.141 & 15.578 & 20.138 & 1.178 \\
\hline \multirow{5}{*}{$14 \mathrm{~mm}$} & Q345-1 & 13.8 & 355 & 466 & 18.5 \\
\hline & Q345-2 & 14.1 & 360 & 468 & 17.6 \\
\hline & Q345-3 & 14.1 & 378 & 492 & 16.3 \\
\hline & Average & 14.0 & 364 & 475 & 17.5 \\
\hline & Standard deviation & 0.141 & 9.877 & 11.813 & 0.903 \\
\hline \multirow{5}{*}{$10 \mathrm{~mm}$} & LYP100-1 & 10.2 & 149 & 254 & 33.1 \\
\hline & LYP100-2 & 9.9 & 160 & 253 & 24.3 \\
\hline & LYP100-3 & 9.8 & 152 & 268 & 27.8 \\
\hline & Average & 10.0 & 154 & 258 & 28.4 \\
\hline & Standard deviation & 0.170 & 4.643 & 6.848 & 3.618 \\
\hline \multirow{5}{*}{$10 \mathrm{~mm}$} & LYP160-1 & 10.1 & 162 & 249 & 30.7 \\
\hline & LYP160-2 & 10.1 & 160 & 248 & 34.4 \\
\hline & LYP160-3 & 9.8 & 175 & 266 & 35.1 \\
\hline & Average & 10.0 & 166 & 254 & 33.4 \\
\hline & Standard deviation & 0.141 & 6.650 & 8.260 & 1.930 \\
\hline
\end{tabular}

performance of the new tubular steel piers, the load-displacement curves of axial compression specimens are compared and analysed. In the load-displacement comparison chart presented in this section, the vertical axis represents the vertical axial compression load $P$, and the horizontal axis represents the vertical compression deformation $\delta$.

3.2.1. Effects of Longitudinal Stiffeners on Steel Tubular Plate. For discussing the effects of the longitudinal stiffeners on the steel tubular plates, Figure 8 shows the load-displacement comparison curves of specimens I-0 and I-A. After the longitudinal stiffeners were installed on the steel tubular plates, the bearing capacity of specimen I-A improved and was $115 \mathrm{kN}$ higher than that of specimen I-0. However, after the local buckling of specimen I-A in the later stage of loading, the mechanical performance of the specimen deteriorated rapidly. The decreasing sections of the curves of specimens I-A and I-0 were the same, and the final deformation capabilities of the two specimens were similar. This indicates that the conventional reinforcement method of adding longitudinal stiffeners can only slightly increase the bearing capacity of the tubular steel pier; it cannot effectively increase the deformation ability of the tubular steel pier.

3.2.2. Effects of Stiffener on LYP Steel Tubular Plate. Figure 9 shows the comparison of load-displacement curves of the II-A and I-0 specimens. After the partial steel tubular plate was replaced by the stiffened LYP steel tubular plate, the bearing capacity of type II-A specimens decreased compared with that of specimen I-0. The downward trend of 


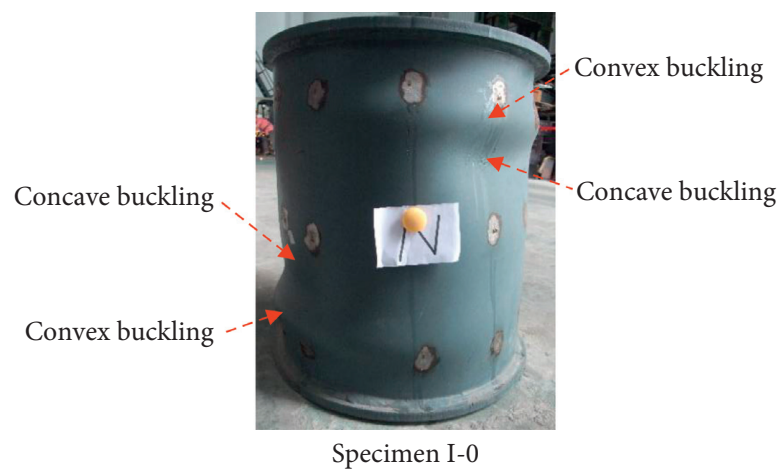

(a)

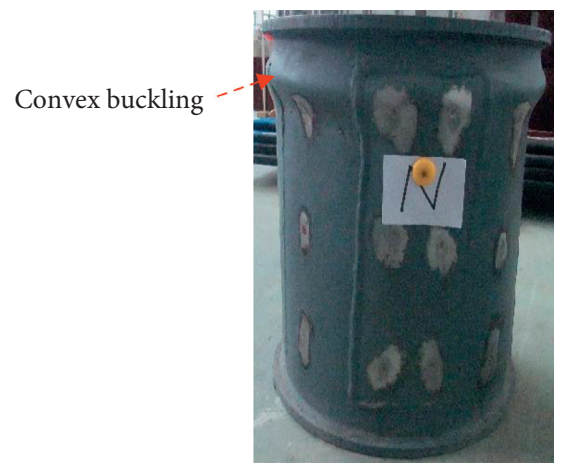

Specimen II-A-1

(c)

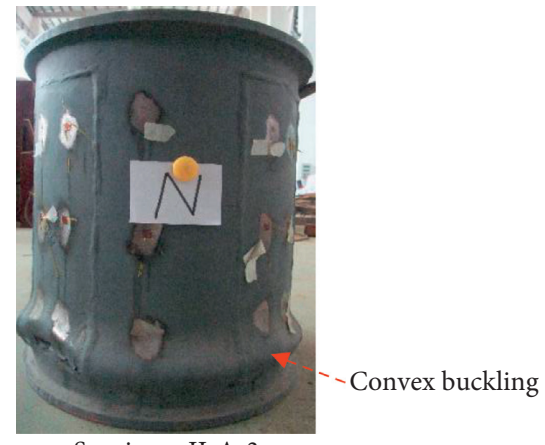

Specimen II-A-3

(e)

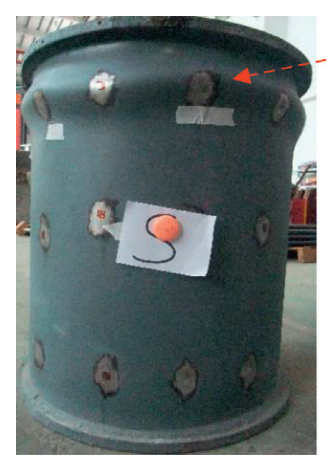

Specimen III-A-2

(g)

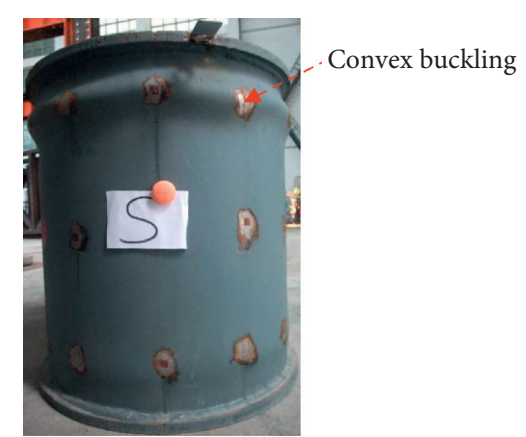

Specimen I-A

(b)

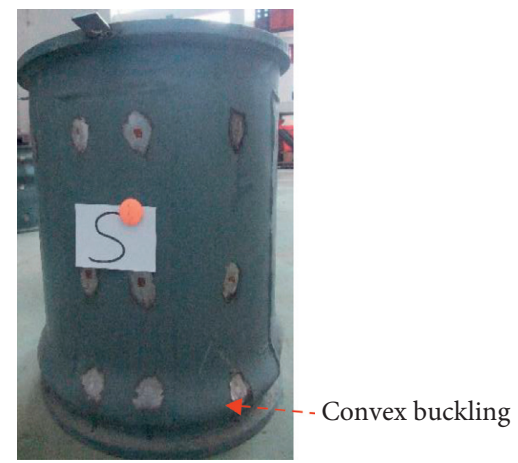

Specimen II-A-2

(d)

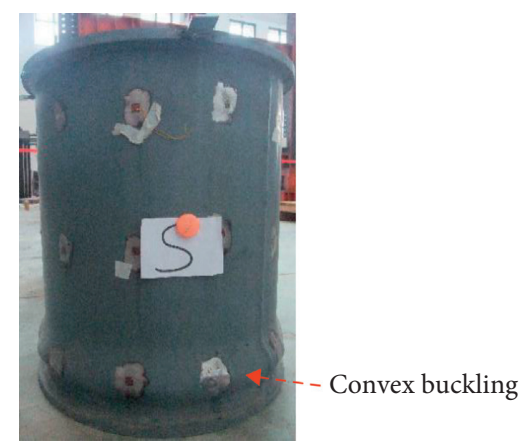

Specimen III-A-1

(f)

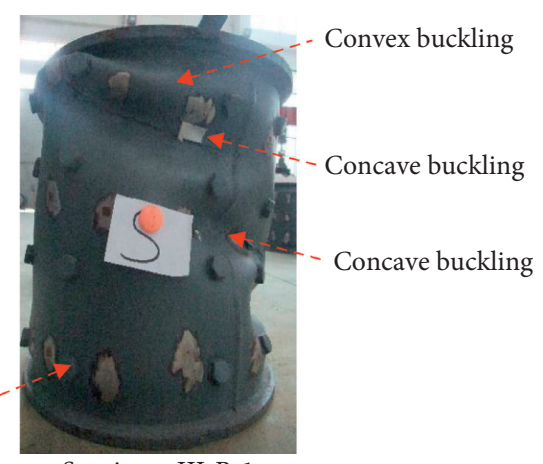

Specimen III-B-1

(h)

(a)

Figure 7: Continued. 

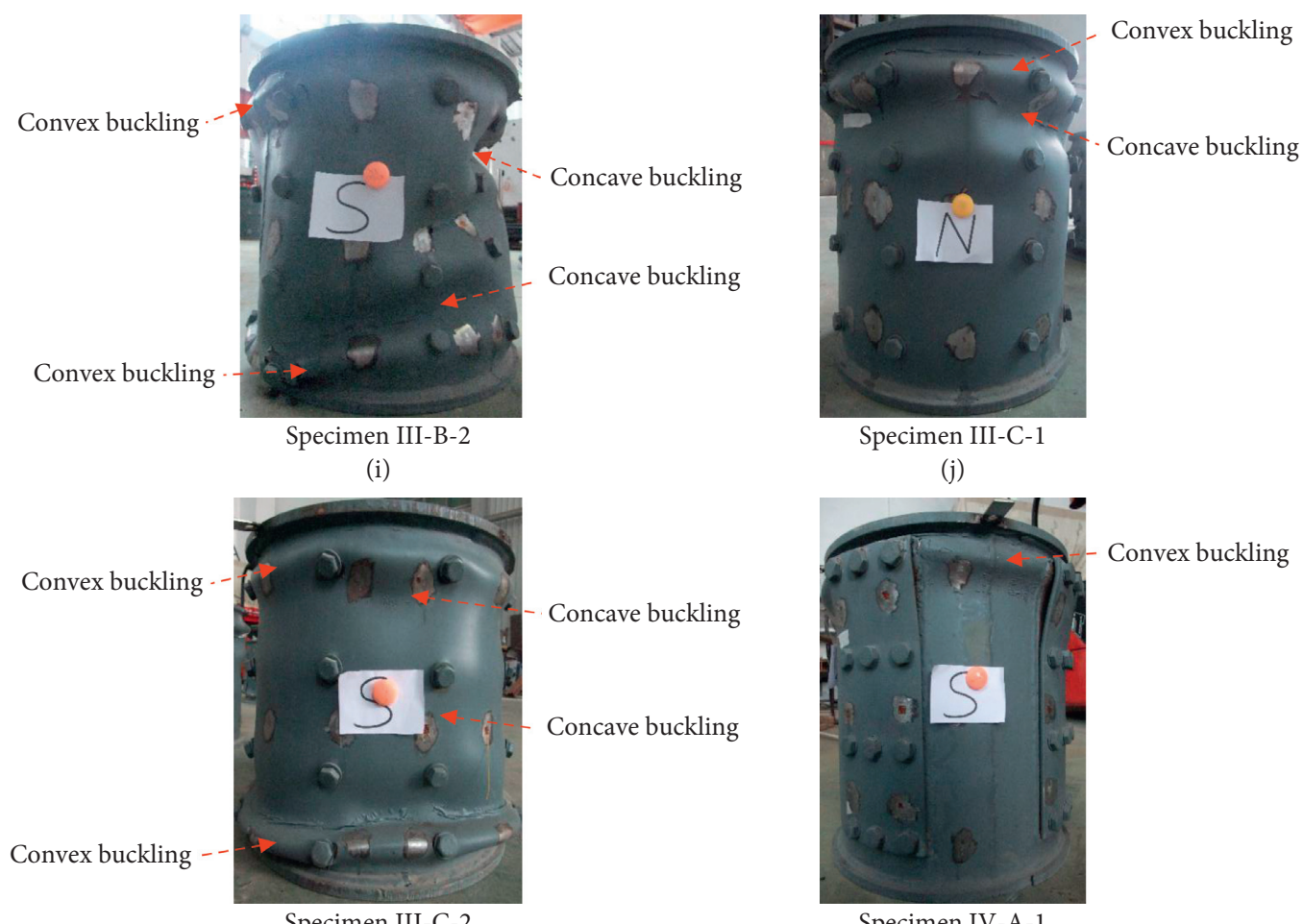

(j)

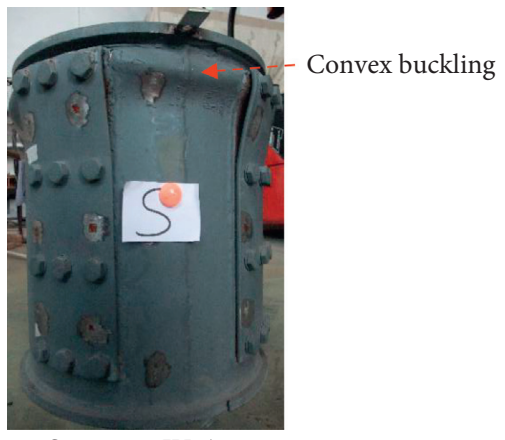

Specimen IV-A-1

(k)

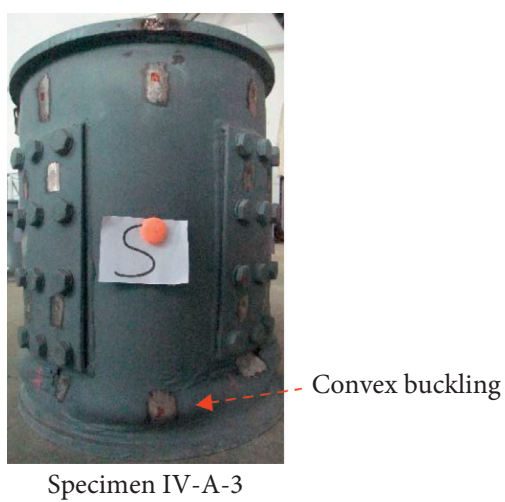

(n)

(b)

Figure 7: Failure mode of new tubular steel piers under axial compression. (a) Specimen I-0. (b) Specimen I-A. (c) Specimen II-A-1. (d) Specimen II-A-2. (e) Specimen II-A-3. (f) Specimen III-A-1. (g) Specimen III-A-2. (h) Specimen III-B-1. (i) Specimen III-B-2. (j) Specimen III-C-1. (k) Specimen III-C-2. (l) Specimen IV-A-1. (m) Specimen IV-A-2. (n) Specimen IV-A-3.

type II-A specimens decelerated in the later loading stage, but the effect was not significant. Specimen II-A-2 with the \#-shaped stiffeners exhibited the highest bearing capacity, followed by specimen II-A-3 with the \#-shaped stiffeners. Specimen II-A-1 with +-shaped stiffeners exhibited the lowest bearing capacity. The deformation performance of specimen II-A-2 was the best, while the deformation capacities of specimens II-A-3 and II-A-1 were not vastly different. This indicates that the $\neq$-shaped stiffeners on the LYP steel tubular plates can slightly improve the mechanical property of the tubular steel pier compared with the two other structures. Owing to the local buckling of the steel tubular plates at the upper or lower end of the specimen, the stiffened LYP steel plates were not fully functional.
Combined with the failure mode of the II-A specimens, the vertical stiffeners on the low-yield-point steel tubular plates should be continuous plates extending the entire specimen to improve the deformation ability of the tubular steel pier.

3.2.3. Effects of Strength of LYP Steel Plate. Figure 10 shows the comparison of load-displacement curves of the Group III and I-0 specimens. As shown in Figure 10(a), after T-shaped LYP steel plates were internally provided, the bearing capacity of the type III-A specimens improved, but the slope of the decreasing section of the curves remained the same. The ultimate deformation value of specimen III-A-1 was larger than that of specimen III-A-2, but the bearing capacities of 


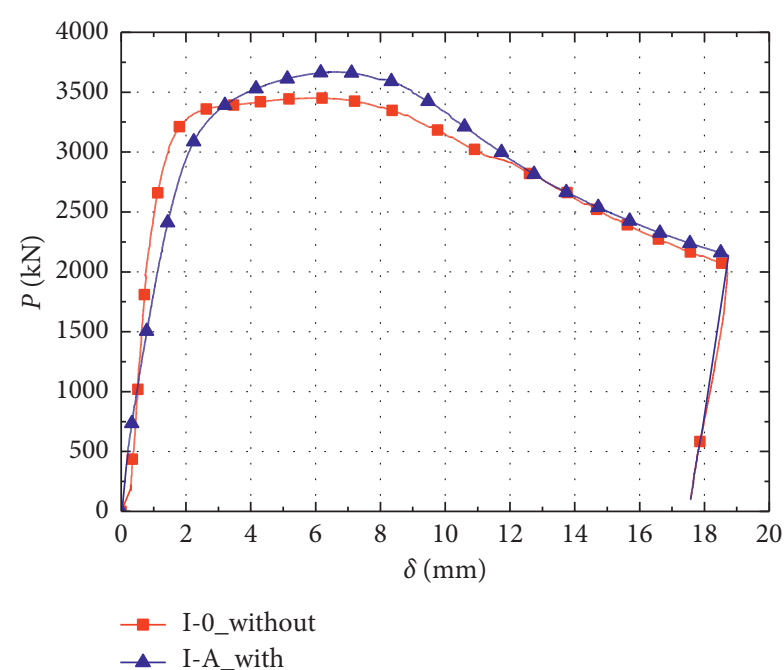

Figure 8: Effects of longitudinal stiffeners on steel tubular plate.

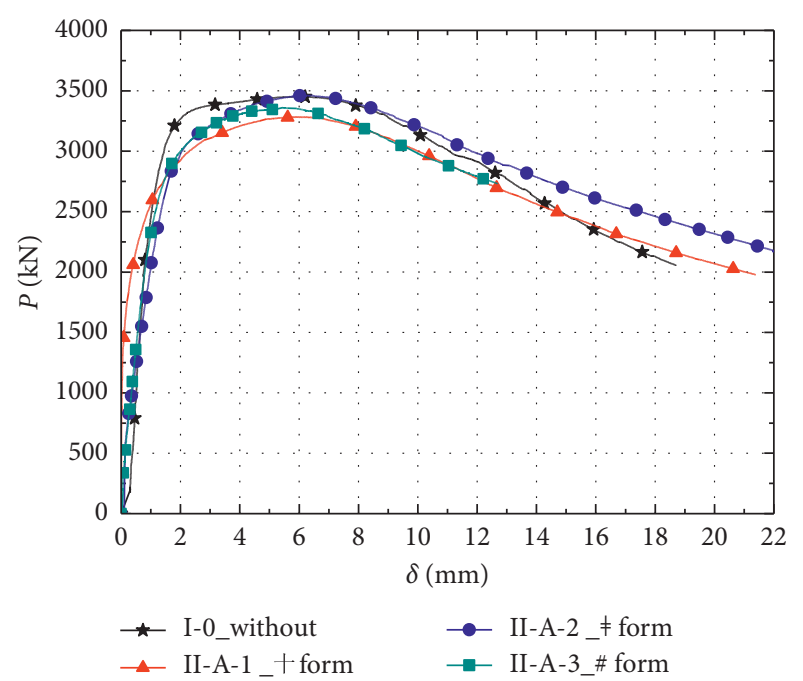

FIgURE 9: Effects of stiffener on LYP steel tubular plate.

the two specimens did not differ vastly. This indicates that the strength of the embedded T-shaped LYP steel plates does not significantly affect the mechanical capacity of the new tubular steel pier. Owing to the local buckling of the steel tubular plates at the upper or lower end of the specimens, the embedded T-shaped LYP steel plates did not exert completely. Based on the failure mode of type III-A specimens, the embedded T-shaped LYP steel plates should be continuous plates extending the entire specimen to improve the deformation ability of type III-A specimens.

As shown in Figures 10(b) and 10(c), the deformation performance of the tubular steel pier improved markedly after constrained LYP steel plates were provided internally. Because the outer steel tubular plates of type III-B and III-C specimens have connecting bolt holes, the bearing capacities of both types of specimens were slightly lower than that of the comparative specimen I-0. However, the internally constrained LYP steel plates were connected to the outer steel tubular plates using high-strength bolts. When the outer steel tubular plates buckled, the internally constrained LYP steel plates provided support for the outer steel tubular plates, which caused buckling deformation at the top, middle, and bottom of the specimen, thereby resulting in a wave-shaped buckling mode. The plastic deformations of the specimens were sufficient. Type III-B and III-C specimens exhibited good deformation ability. The bearing capacity and deformation curve of specimens III-B-1 and III-B-2 were the same. Specimen III-C-1 was the first axial compression specimen comprising constrained LYP steel plates. When the vertical deformation was $50 \mathrm{~mm}$, this specimen type had already exhibited sufficient deformation ability. The vertical displacement measurement at that instant reached the maximum range. Therefore, the test was terminated, resulting in the absence of the later-stage deformation curve of specimen III-C-1. Within the vertical deformation of $50 \mathrm{~mm}$, the bearing capacity and deformation curve of specimens III-C- 1 and III-C-2 were the same. This indicates that the strength of the embedded LYP steel plates did not significantly affect the mechanical properties of type III-B and III-C specimens.

\subsubsection{Effects of Height of Constrained LYP Steel Tubular} Plate. Figure 11 shows the comparison of load-displacement curves of type IV-A and I-0 specimens. As shown, after a part of the steel tubular plate was changed to the LYP steel tubular plate with constrained steel plates on both sides, the bearing capacity and deformation capacity of tubular steel pier improved. Specimen IV-A-1 had the largest bearing capacity, followed by specimen IV-A-2; meanwhile, specimen IV-A-3 had the smallest bearing capacity. The deformation ability of specimen IV-A-1 was higher than that of specimen IV-A-2. The height of the constrained LYP steel tubular plate in specimen IV-A-3 was small. To prevent the local buckling of ordinary steel tubular plates at the upper or lower end of the specimen, vertical stiffeners were added to the upper and lower ordinary steel tubular plates. Therefore, the deformation ability of specimen IV-A-3 was relatively large at the later loading stage. This indicates that increasing the height of the constrained LYP steel tubular plate can improve the mechanical capacity of the new tubular steel pier. When vertical stiffeners were added to the common steel tubular plate at the upper and lower ends of specimens, the deformation capacity of the tubular steel pier improved.

\subsection{Displacement Ductility Coefficient and Bearing Capacity}

3.3.1. Effects of Axial Compression Ratio. To quantitatively analyse the mechanical behaviour of the axial compression specimens, the vertical deformation $\delta$ and vertical load $P$ of the axial compression specimens at the yield point, peak point, and extreme point were calculated, as shown in Table 3. The yield point is the stress state at the instant when the steel tubular plate begins to yield. The peak point is the stress state corresponding to the maximum vertical load $P_{\max }$ on the $P-\delta$ curve. The extreme point is the corresponding stress state when the vertical load is decreased to 


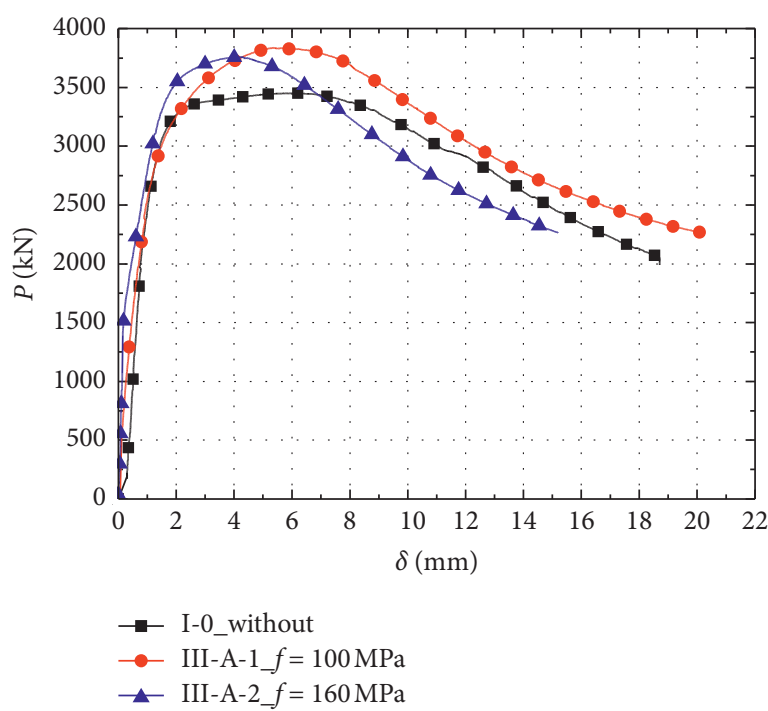

(a)

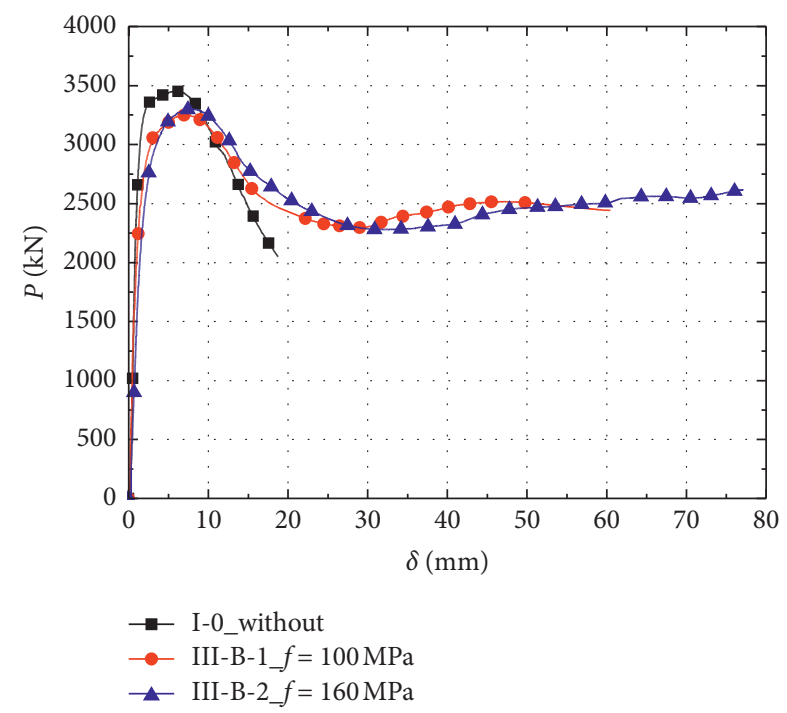

(b)

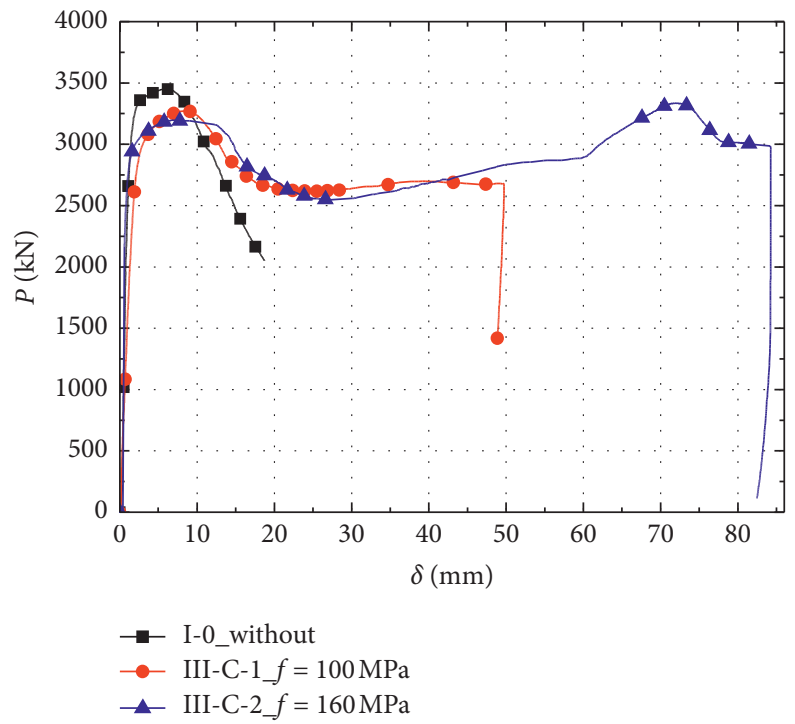

(c)

FIgUre 10: Effects of strength of LYP steel plate. (a) Type III-A specimens. (b) Type III-B specimens. (c) Type III-C specimens.

$0.85 P_{\max }$. In Table $3, \delta y$ and $P_{y}$ represent the axial compression deformation and axial load corresponding to the yield point state, respectively. The maximum axial compression deformation and maximum axial load corresponding to the peak point state are denoted as $\delta_{\max }$ and $P_{\text {max }}$, respectively. The axial compression deformation corresponding to the extreme point state is denoted as $\delta_{\mathrm{u}}$.

As shown in Table 3, the ductility coefficient of specimen I-A was 4.4, which was smaller than that of specimen I-0 (5.6); however, the bearing capacity of specimen I-A increased. This indicates the fact that, after vertical stiffeners are added to the steel tubular plate, the deformation performance of the specimen will deteriorate considerably after the local buckling of the steel tubular plate. Therefore, adding vertical stiffeners alone cannot effectively improve the deformation capacity of the tubular steel pier. The ductility coefficients of specimens II-A-1, II-A-2, and II-A3 were $5.8,5.8$, and 6.0 , respectively, which were greater than that of specimen I-0 (5.6). This indicates that the deformation performance of the tubular steel pier improved after the stiffened LYP steel tubular plates are installed, but the effect is not significant. The ductility coefficient of specimen III-A was smaller than that of specimen I-0, but the bearing capacity improved. Considering the failure mode of the specimen, it can be concluded that the steel tubular plates at the upper or lower end of type III-A specimens are prone to local buckling. The embedded T-shaped LYP steel plates exert incompletely.

Based on the cowmprehensive analysis of ductility coefficients shown in Figure 10 and Table 3, it can be concluded that type III-B and III-C specimens do not fully demonstrate the 


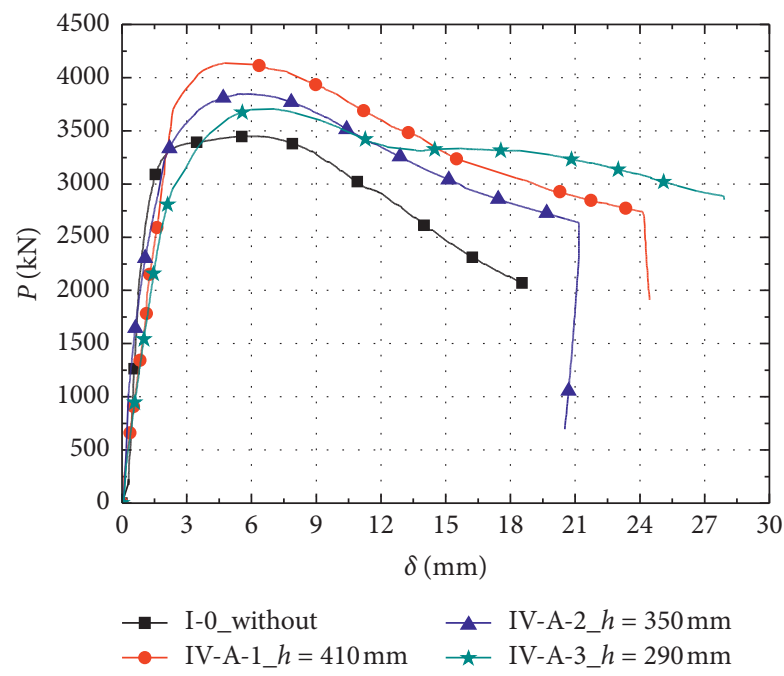

FIGURE 11: Effects of height of constrained LYP steel tubular plate.

TABLE 3: Summary results of axially compressed specimens.

\begin{tabular}{|c|c|c|c|c|c|c|c|}
\hline \multirow{2}{*}{ Specimen label } & \multicolumn{2}{|c|}{ Nominal yield point } & \multicolumn{2}{|c|}{ Peak point } & \multirow{2}{*}{$\begin{array}{c}\text { Extreme point } \\
\delta_{\mathrm{u}}(\mathrm{mm})\end{array}$} & \multirow{2}{*}{$\begin{array}{c}P_{y} / P_{\max } \\
\text { ax }\end{array}$} & \multirow{2}{*}{$\begin{array}{l}\text { Ductility } \\
\mu=\delta_{\mathrm{u}} / \delta_{y}\end{array}$} \\
\hline & $\delta_{y}(\mathrm{~mm})$ & $P_{y}(\mathrm{kN})$ & $\delta_{\max }(\mathrm{mm})$ & $P_{\max }(\mathrm{kN})$ & & & \\
\hline $\mathrm{I}-0$ & 2.02 & 3250 & 5.69 & 3451 & 11.40 & 0.94 & 5.6 \\
\hline I-A & 2.53 & 3250 & 6.68 & 3670 & 11.08 & 0.89 & 4.4 \\
\hline II-A-1 & 1.84 & 2920 & 6.16 & 3284 & 10.74 & 0.89 & 5.8 \\
\hline II-A-2 & 2.16 & 3071 & 6.44 & 3463 & 12.42 & 0.89 & 5.8 \\
\hline II-A-3 & 1.89 & 2988 & 5.54 & 3359 & 11.31 & 0.89 & 6.0 \\
\hline III-A-1 & 2.39 & 3433 & 5.35 & 3840 & 10.84 & 0.89 & 4.5 \\
\hline III-A-2 & 2.02 & 3340 & 4.11 & 3760 & 8.24 & 0.89 & 4.1 \\
\hline III-B-1 & 2.50 & 2927 & 7.24 & 3251 & 14.26 & 0.90 & 5.7 \\
\hline III-B-2 & 3.38 & 2968 & 7.91 & 3302 & 14.97 & 0.90 & 4.4 \\
\hline III-C-1 & 2.63 & 2977 & 8.55 & 3274 & 16.0 & 0.91 & 6.1 \\
\hline III-C-2 & 1.75 & 2977 & 7.28 & 3199 & 20.07 & 0.93 & 11.5 \\
\hline IV-A-1 & 2.37 & 3697 & 4.73 & 4137 & 12.85 & 0.89 & 5.4 \\
\hline IV-A-2 & 2.21 & 3363 & 5.49 & 3849 & 12.81 & 0.87 & 5.8 \\
\hline IV-A-3 & 2.02 & 3340 & 7.07 & 3707 & 22.80 & 0.90 & 11.3 \\
\hline
\end{tabular}

effect of internally constrained LYP steel plates on the ductility coefficients of the new tubular steel pier. The mechanical behaviour of the new tubular steel pier with internally constrained LYP steel plates can be divided into two stages. The first stage is the local buckling of the outer steel tubular plate. The bearing capacity of the new tubular steel pier decreases rapidly. However, with the increase in vertical compression deformation, the internally constrained LYP steel plate provides support for the outer steel tubular plate. At this time, the new tubular steel pier enters the second mechanical stage, and the deformation capacity of the tubular steel pier increases considerably. The ductility coefficients shown in Table 3 reflect the deformation properties of only the first stage of type III-B and III-C specimens.

The ductility coefficients of specimens IV-A-1, IV-A-2, and IV-A-3 were 5.4, 5.8, and 11.3, respectively, which were larger than or close (5.6) to that of specimen I-0. The deformation ability and bearing capacity of the tubular steel pier improved when the constrained LYP steel tubular plates were used. Moreover, adding vertical stiffeners to the common steel tubular plate on the upper and lower ends of the specimen can significantly improve the deformation ability of the tubular steel pier.

\section{Numerical Analysis}

4.1. FEM Model and Verification. According to the geometric parameters of the axial compression specimen, a finite element model of the new tubular steel pier was established using ANSYS16.0, as shown in Figure 12(a). The shell element, denoted as Shell181, was simulated on the steel plates. The constitutive relationship of the steel material is defined by a multilinear kinematic hardening model. The Poisson ratio of the steel material was 0.3 , and the elastic modulus was $2.06 \times 10^{5} \mathrm{MPa}$. The remaining parameters were based on the measured values of the material properties summarised in Table 2. The contact element of CONTA173 was used to set the LYP steel plate as the contact surface. The element TARGE170 was used to assign the outer constrained steel plates as the target surface. The elements TARGE170 


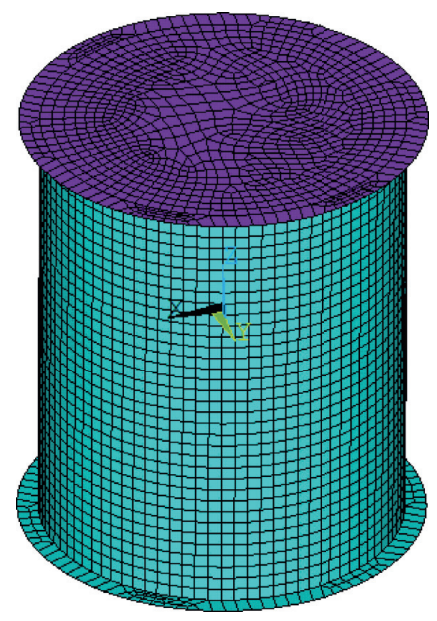

(a)

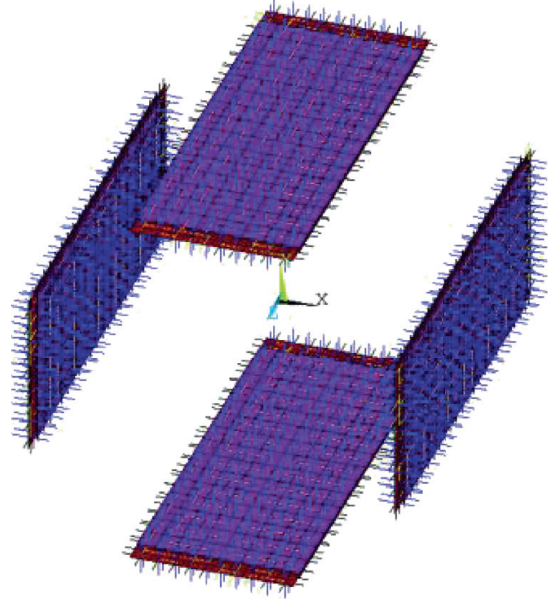

(b)

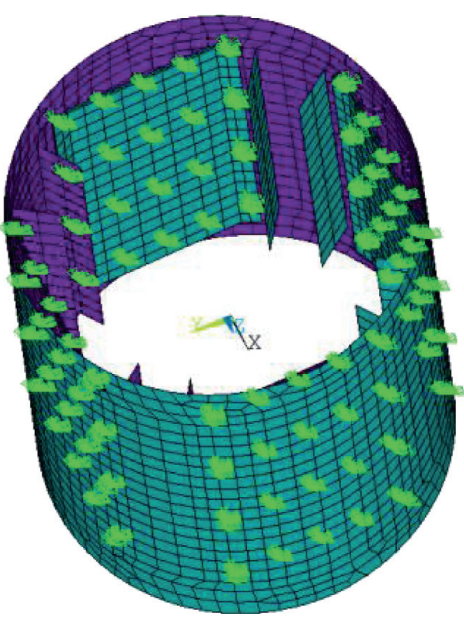

(c)

FIGURE 12: Finite element model and special boundary constraints. (a) Finite element model. (b) Contact pairs on LYP steel plates. (c) Simulation of bolts connection.

and CONTA173 shared the same real constant number to form one contact pair. Considering the contact restraint of the LYP steel plate and the outer constrained steel plates, the contact pair is as shown in Figure 12(b). For simulating the bolt connection among the LYP steel plate, outer constrained steel plate, and steel tubular plate, the linear displacements $U_{x}, U_{y}$, and $U_{z}$ of the corresponding nodes on the three steel plates at the locations of the high-strength bolts were coupled, as shown in Figure 12(c). The bottom of the tubular steel pier was rigidly connected. To simulate an axial compression process, an axial displacement loading was imposed on the top of the tubular steel pier.

For verifying the accuracy of the finite element models proposed herein, vertical load-deformation curves of specimens II-A-3 and III-A-2 obtained from the test and finite element method are compared and analysed, as shown in Figure 13. The failure modes of specimens II-A-1, III-A-1, III-C-2, and IV-A-3 obtained from experiment and finite element simulation are compared and analysed, as shown in Figure 14. As shown, in Figures 13 and 14, the load peaks on the load-deformation curves obtained using the finite element method almost agree with the measured curves. Additionally, the downward trend of the curves agreed well with the experimental results at the later loading stage. The position and pattern of the plastic deformation of the specimen obtained by the finite element model agreed well with the test data. Thus, the finite element models proposed by the authors can simulate the main mechanical characteristics of the new tubular steel piers.

4.2. Design Parameters of Numerical Specimens. The numerical analysis model was designed with reference to the typical dimensions of the tubular steel pier in actual projects. To consider the effects of the actual bending moment at the bottom of the tubular steel pier, numerical specimens with eccentric compression were designed. The design parameters of the numerical specimens are detailed in Table 4. The nomenclature of the numerical specimens in Table 4 is divided into two parts. The number in front of the parentheses corresponds to the number of the experimental specimens in Table 1, and they share the same construction details. The values in parentheses indicate the values of the main varying parameters of the numerical specimens. In Table $4, H$ represents the height of the tubular steel pier, $D$ the outer diameter of the tubular steel pier, $t$ the thickness of the steel tubular plate, $t_{\mathrm{f}}$ the thickness of the LYP steel plate, $t_{\mathrm{w}}$ the thickness of the stiffener on the LYP steel plate or the thickness of the constrained steel plates on both sides, $h$ the height of the LYP steel plate, $t_{\mathrm{h}}$ the thickness of the longitudinal stiffener on the steel tubular plate, $f$ the theoretical yield strength of the LYP steel plate, and $e$ the eccentricity of the vertical load.

\subsection{Parameter Analysis and Discussion}

4.3.1. Effects of Vertical Stiffeners on Steel Tubular Plate. For discussing the effects of vertical stiffeners installed on steel tubular plates on the mechanical performance of tubular steel piers, the load-displacement curves of specimen I-0 and type I-A specimens under axially and eccentrically compressed action are compared in Figure 15. It can be seen from Figure 15 that, under the axially or eccentrically compressed loading, the bearing capacity of type I-A specimens was greater than that of specimen I-0. However, the degradation patterns of the load-displacement curves of the two types of specimens were similar in the late loading state. The ultimate vertical deformation values were not much different. This indicates that the vertical stiffeners on the steel tubular plate can improve the bearing capacity of the tubular steel pier, but they cannot effectively improve the deformation ability of the tubular steel pier.

4.3.2. Effects of Stiffeners on LYP Steel Tubular Plates. The load-displacement curves of specimen I-0 and type II-A specimens are compared in Figure 16, which investigates the 


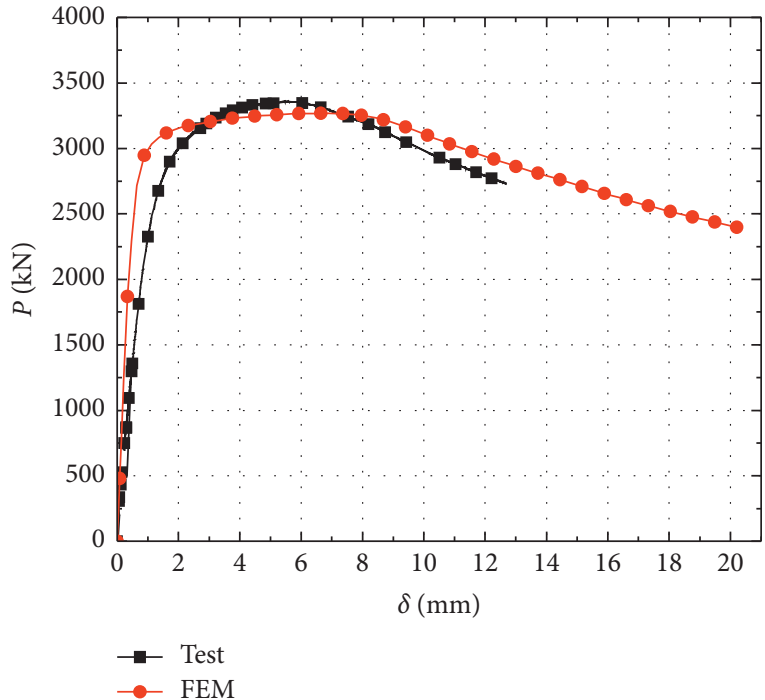

(a)

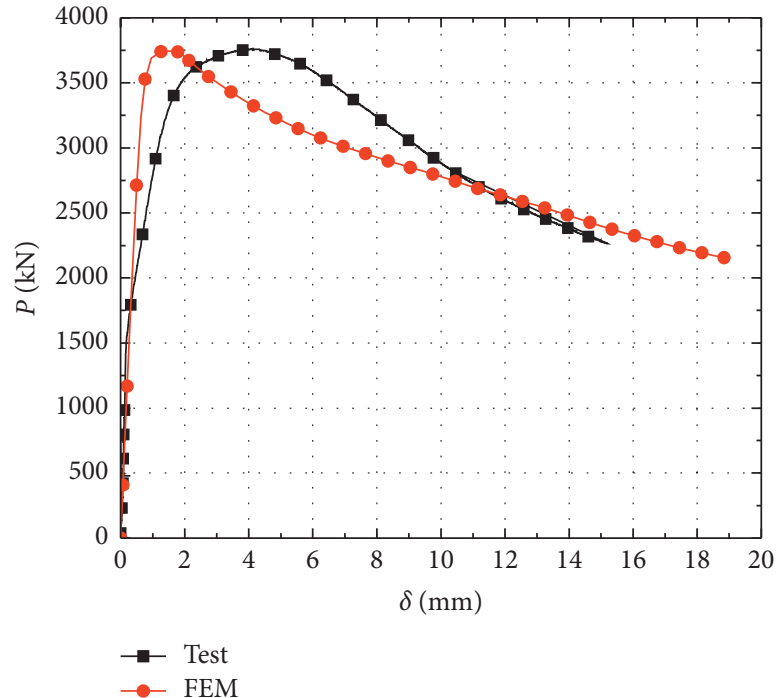

(b)

FIgURE 13: Comparison on load-deformation curves of some axially compressed specimens. (a) Specimen II-A-3. (b) Specimen III-A-2.
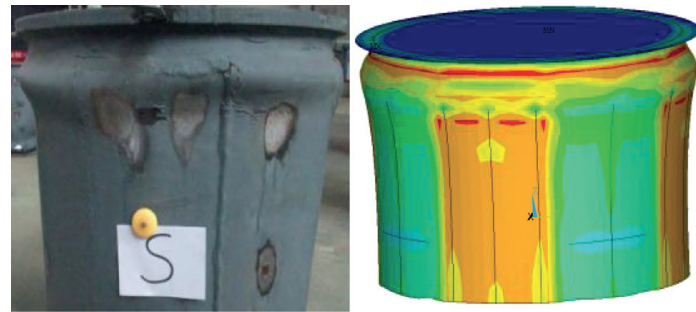

(a)
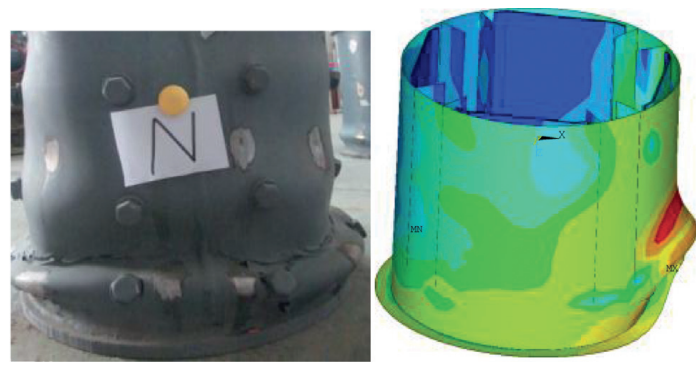

(c)
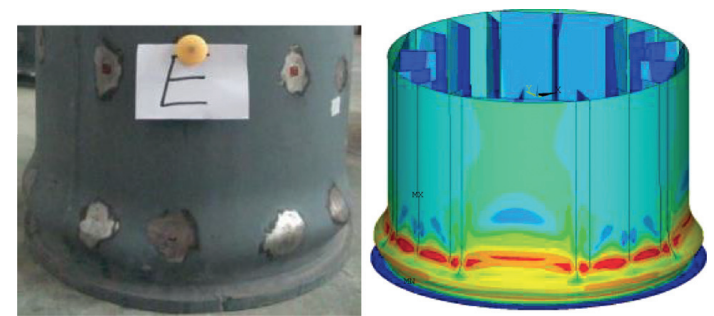

(b)
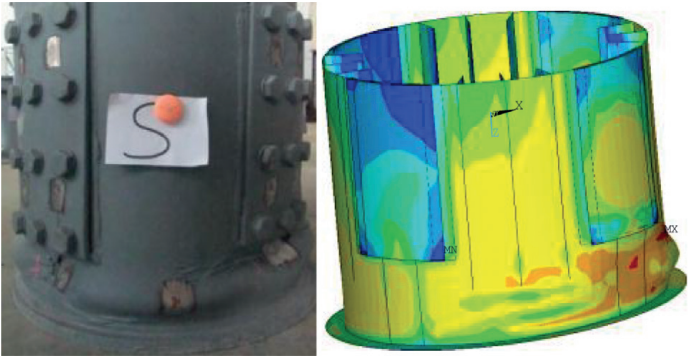

(d)

Figure 14: Comparison on failure modes of some axially compressed specimens. (a) Specimen II-A-1. (b) Specimen III-A-1. (c) Specimen III-C-2. (d) Specimen IV-A-3.

effect of different types of stiffeners installed on LYP steel tubular plates on mechanical properties of tubular steel piers. Under axially compressed loading, the bearing capacity of type II-A specimens was greater than that of specimen I-0, but the vertical ultimate compression deformation was basically the same. Therefore, different types of stiffeners have little effect on the mechanical behaviour of type II-A specimens under axially compressed action. Under eccentrically compressed loading, the mechanical behaviour of type II-A specimens was significantly improved in the later loading stage. The improvement effect of the type II-A-2 specimens with $\neq$-shaped stiffeners was the most significant.
4.3.3. Effects of Thickness of LYP Steel Tubular Plate. To investigate the effect of the thickness $t_{\mathrm{f}}$ of the LYP steel tubular plates on the mechanical behaviour of the tubular steel pier, the load-displacement curves of the type II-A-2 specimens under axial compression are compared in Figure 17. With the increase in the thickness of the LYP steel tubular plate, the bearing capacity of the new tubular steel pier increased continuously. The deformation performance of specimen II-A-2 (N6) was the best, but the deformation performance of specimen II-A-2 (N8) with the thickest LYP steel tubular plate degraded considerably. This indicates that the thickness $t_{\mathrm{f}}$ of the LYP steel tubular plate should match the thickness $t$ of the common steel tubular plate to 
TABLE 4: The design parameters of numerical specimens.

\begin{tabular}{|c|c|c|c|c|c|c|c|c|c|}
\hline Specimen label & $H(\mathrm{~mm})$ & $D(\mathrm{~mm})$ & $t(\mathrm{~mm})$ & $t_{\mathrm{f}}(\mathrm{mm})$ & $t_{\mathrm{w}}(\mathrm{mm})$ & $h(\mathrm{~mm})$ & $t_{\mathrm{h}}(\mathrm{mm})$ & $f(\mathrm{MPa})$ & $e(\mathrm{~mm})$ \\
\hline I-0 (N1) & 2100 & 1500 & 30 & 0 & 0 & 0 & 0 & 0 & 0 \\
\hline I-0 (N2) & 2100 & 1500 & 30 & 0 & 0 & 0 & 0 & 0 & 300 \\
\hline I-A (N1) & 2100 & 1500 & 30 & 0 & 0 & 0 & 30 & 0 & 0 \\
\hline I-A (N2) & 2100 & 1500 & 30 & 0 & 0 & 0 & 30 & 0 & 300 \\
\hline II-A-1 (N1) & 2100 & 1500 & 30 & 40 & 28 & 1600 & 30 & 160 & 0 \\
\hline II-A-1 (N2) & 2100 & 1500 & 30 & 40 & 28 & 1600 & 30 & 160 & 300 \\
\hline II-A-2 (N1) & 2100 & 1500 & 30 & 40 & 28 & 1600 & 30 & 160 & 0 \\
\hline II-A-2 (N2) & 2100 & 1500 & 30 & 40 & 28 & 1600 & 30 & 160 & 300 \\
\hline II-A-3 (N1) & 2100 & 1500 & 30 & 40 & 28 & 1600 & 30 & 160 & 0 \\
\hline II-A-3 (N2) & 2100 & 1500 & 30 & 40 & 28 & 1600 & 30 & 160 & 300 \\
\hline II-A-2 (N3) & 2100 & 1500 & 30 & 30 & 28 & 1600 & 30 & 160 & 0 \\
\hline II-A-2 (N4) & 2100 & 1500 & 30 & 40 & 28 & 1600 & 30 & 160 & 0 \\
\hline II-A-2 (N5) & 2100 & 1500 & 30 & 50 & 28 & 1600 & 30 & 160 & 0 \\
\hline II-A-2 (N6) & 2100 & 1500 & 30 & 60 & 28 & 1600 & 30 & 160 & 0 \\
\hline II-A-2 (N7) & 2100 & 1500 & 30 & 70 & 28 & 1600 & 30 & 160 & 0 \\
\hline II-A-2 (N8) & 2100 & 1500 & 30 & 80 & 28 & 1600 & 30 & 160 & 0 \\
\hline III-A-1 (N1) & 2100 & 1500 & 30 & 40 & 28 & 1600 & 30 & 100 & 0 \\
\hline III-A-1 (N2) & 2100 & 1500 & 30 & 40 & 28 & 1600 & 30 & 100 & 300 \\
\hline III-A-2 (N1) & 2100 & 1500 & 30 & 40 & 28 & 1600 & 30 & 160 & 0 \\
\hline III-A-2 (N2) & 2100 & 1500 & 30 & 40 & 28 & 1600 & 30 & 160 & 300 \\
\hline III-B-1 (N1) & 2100 & 1500 & 30 & 40 & 28 & 1600 & 30 & 100 & 0 \\
\hline III-B-1 (N2) & 2100 & 1500 & 30 & 40 & 28 & 1600 & 30 & 100 & 300 \\
\hline III-B-2 (N1) & 2100 & 1500 & 30 & 40 & 22 & 1600 & 30 & 160 & 0 \\
\hline III-B-2 (N2) & 2100 & 1500 & 30 & 40 & 28 & 1600 & 30 & 160 & 0 \\
\hline III-B-2 (N3) & 2100 & 1500 & 30 & 40 & 34 & 1600 & 30 & 160 & 0 \\
\hline III-B-2 (N4) & 2100 & 1500 & 30 & 40 & 40 & 1600 & 30 & 160 & 0 \\
\hline III-C-2 (N1) & 2100 & 1500 & 30 & 40 & 28 & 1600 & 30 & 160 & 0 \\
\hline III-C-2 (N2) & 2100 & 1500 & 30 & 40 & 28 & 1600 & 30 & 160 & 300 \\
\hline IV-A-1 (N1) & 2100 & 1500 & 30 & 40 & 28 & 1600 & 30 & 100 & 0 \\
\hline IV-A-1 (N2) & 2100 & 1500 & 30 & 40 & 28 & 1600 & 30 & 100 & 300 \\
\hline IV-A-2 (N1) & 2100 & 1500 & 30 & 40 & 28 & 1400 & 30 & 100 & 0 \\
\hline IV-A-2 (N2) & 2100 & 1500 & 30 & 40 & 28 & 1400 & 30 & 100 & 300 \\
\hline IV-A-3 (N1) & 2100 & 1500 & 30 & 40 & 28 & 1200 & 30 & 100 & 0 \\
\hline IV-A-3 (N2) & 2100 & 1500 & 30 & 40 & 28 & 1200 & 30 & 100 & 300 \\
\hline
\end{tabular}

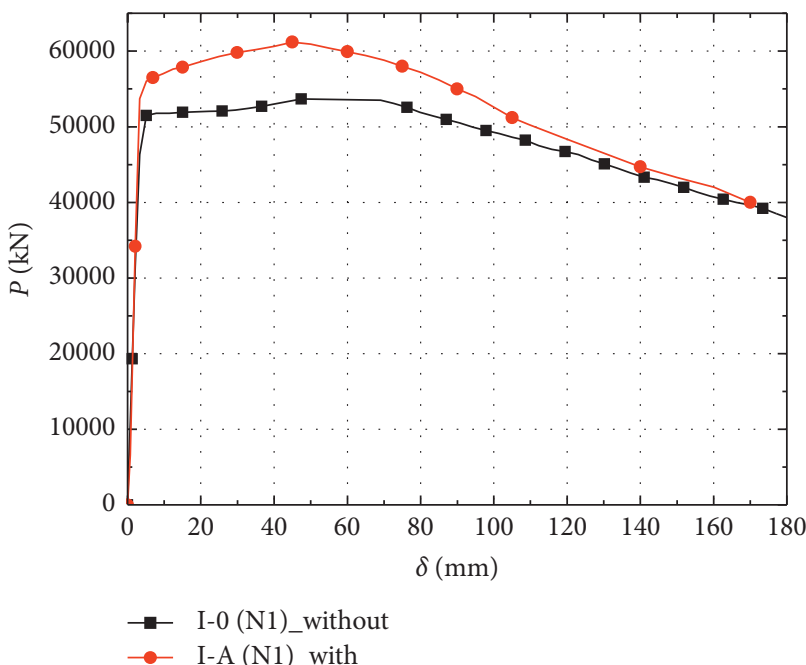

(a)

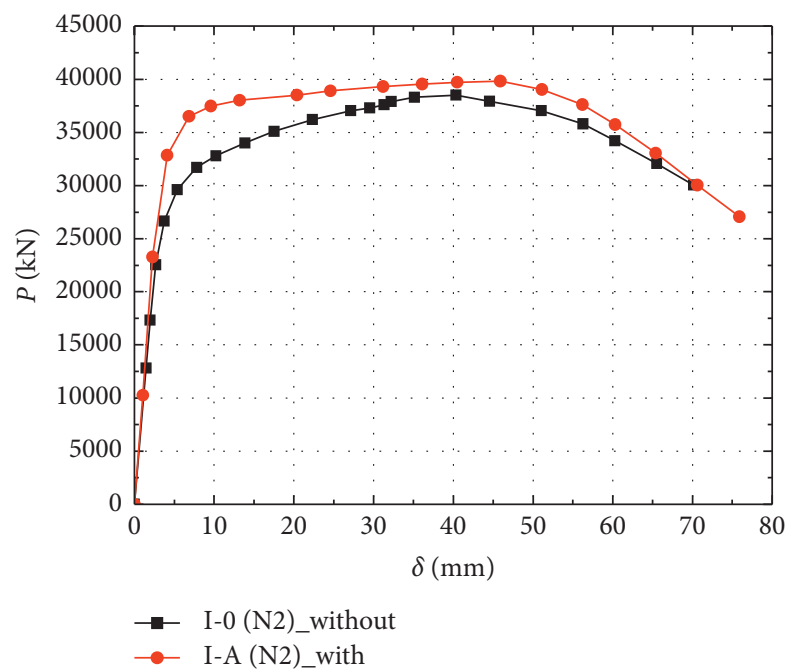

(b)

FIGURE 15: Effects of vertical stiffeners on steel tubular plate. (a) Axially compressed specimens. (b) Eccentrically compressed specimens. 


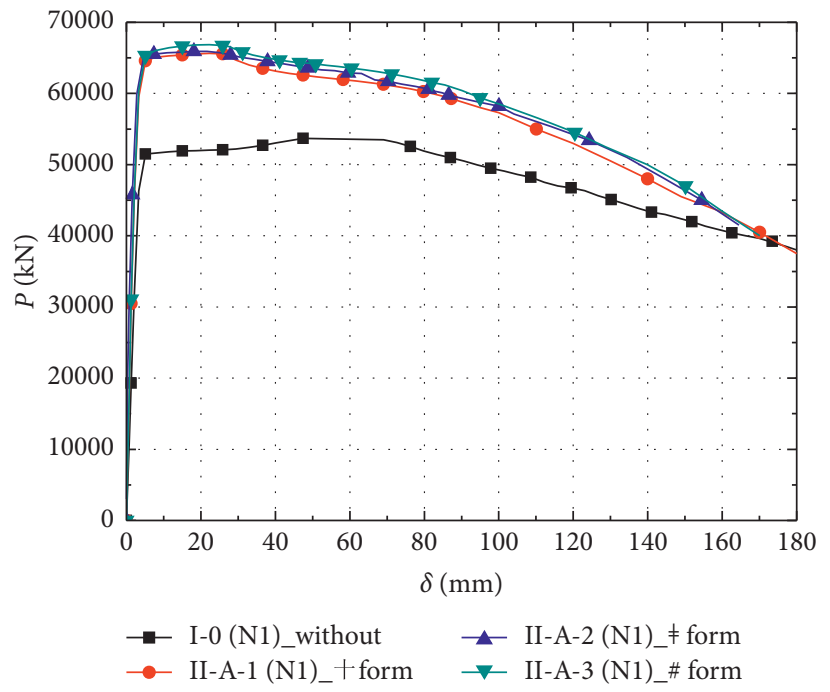

(a)

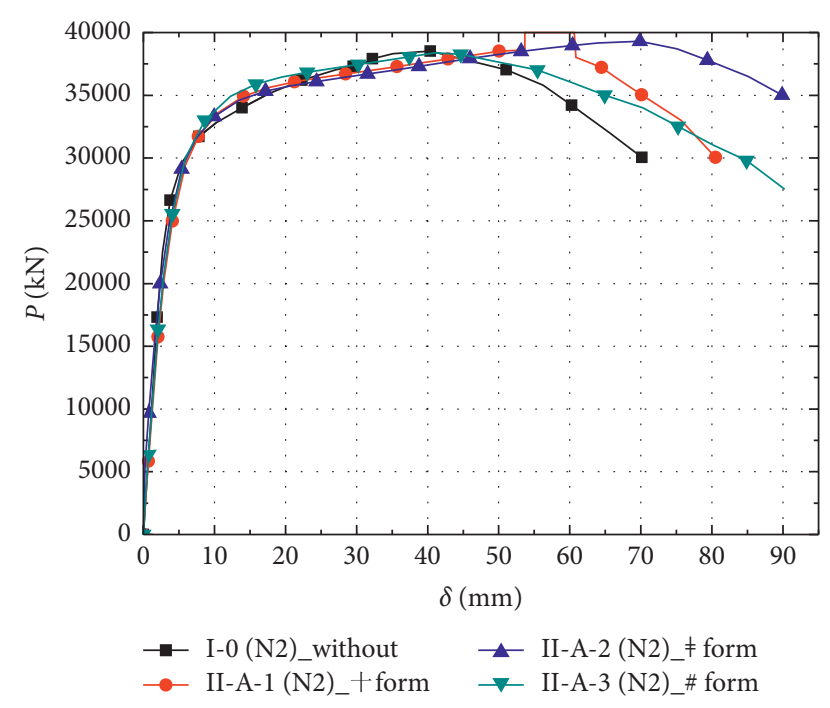

(b)

Figure 16: Effects of stiffeners on LYP steel tubular plate. (a) Axially compressed specimens. (b) Eccentrically compressed specimens.

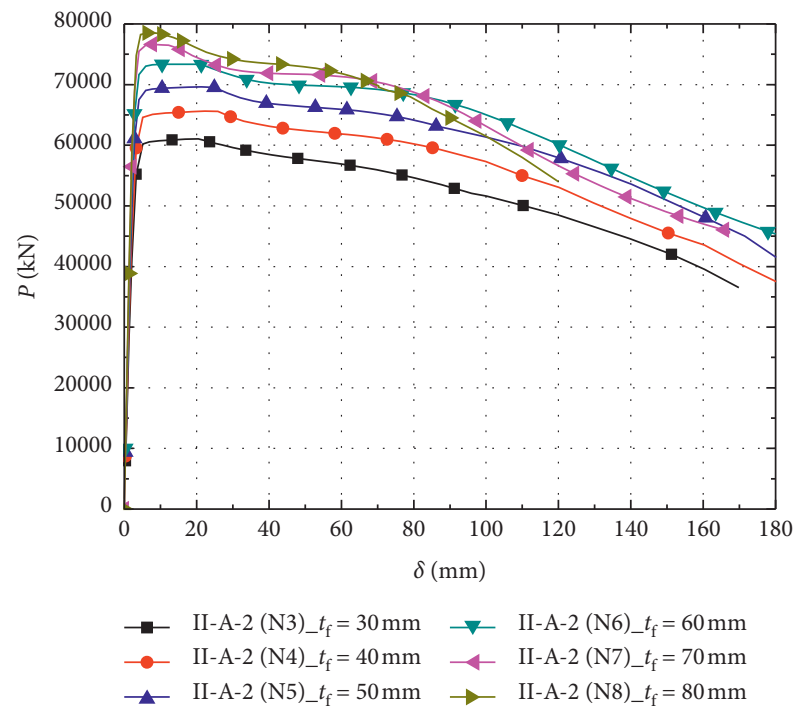

Figure 17: Effects of thickness of LYP steel tubular plate on skeleton curves.

enhance the mechanical behaviour of the tubular steel pier. The thickness of the LYP steel tubular plate should satisfy $t \leq t_{\mathrm{f}} \leq 2 t$.

4.3.4. Effects of Thickness of Outer Constrained Steel Plate. For discussing the effects of the thickness $t_{\mathrm{w}}$ of the outer constrained steel plate on the mechanical behaviour of the tubular steel pier, load-displacement curves of type III-B-2 specimens under axial compression are compared in Figure 18. As the thickness of the outer constrained steel plates increases continuously, the bearing capacity of the new tubular steel pier and the area included in the load-displacement curve increased. However, when the thickness of the outer constrained steel plate was increased to a certain extent, the bearing capacity of the specimen became stable. The thickness

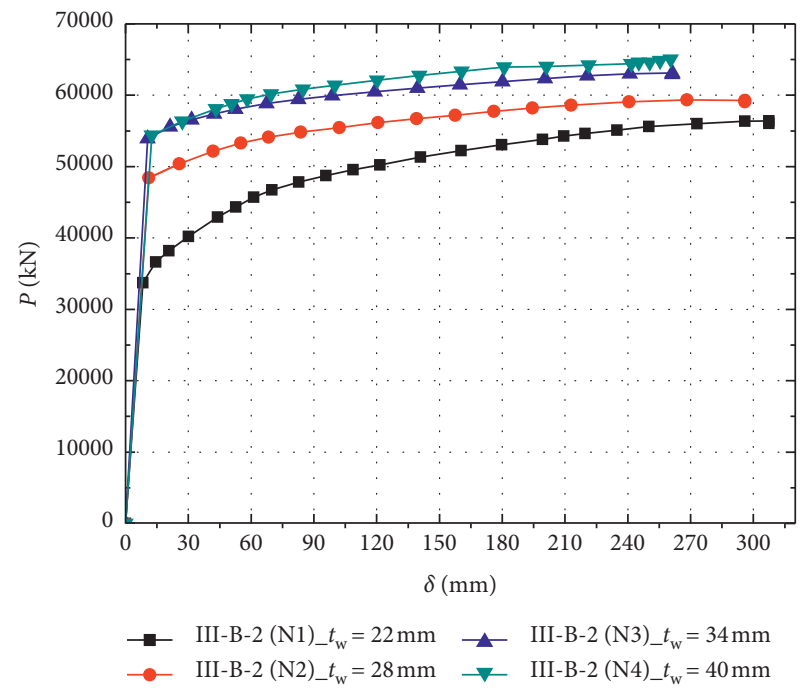

FIGURE 18: Effects of thickness of outer constrained steel plate on skeleton curves.

$t_{\mathrm{w}}$ of the outer constrained steel plate should be equal to the thickness $t$ of the common steel tubular plate; that is, $t_{\mathrm{w}}=t$.

4.3.5. Effect of the Height of LYP Steel Tubular Plate. To investigate the effects of the height of the LYP steel tubular plate on the mechanical behaviour of the tubular steel pier, load-displacement curves of type IV-A and I- 0 specimens under axially or eccentrically compressed loading are compared in Figure 19. As shown, type IV-A specimens with constrained LYP steel tubular plates exhibited improved mechanical behaviour. After vertical stiffeners were added to the common steel tubular plates on the upper and lower ends of the specimens, the height of the LYP steel tubular plate became insignificant to the mechanical performance of the new tubular steel piers. 


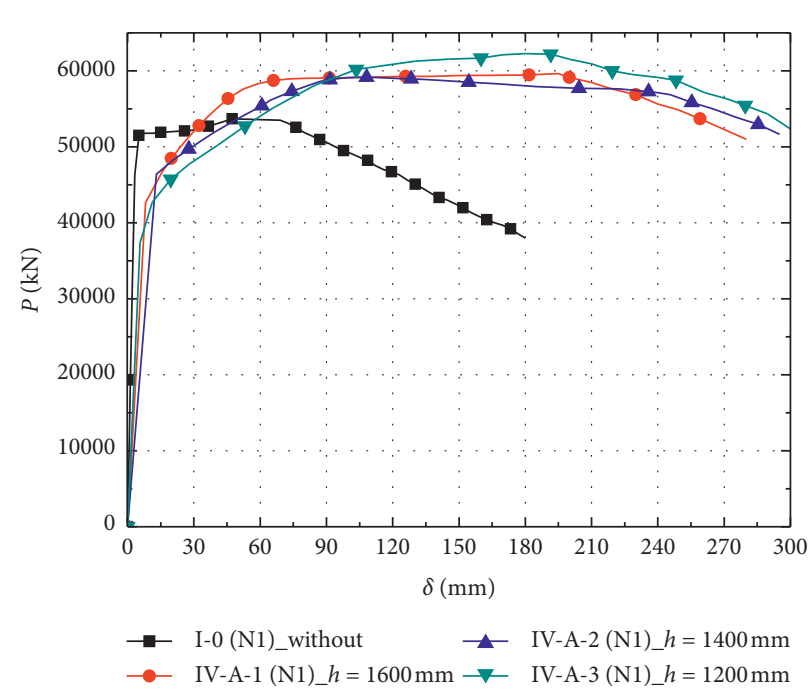

(a)

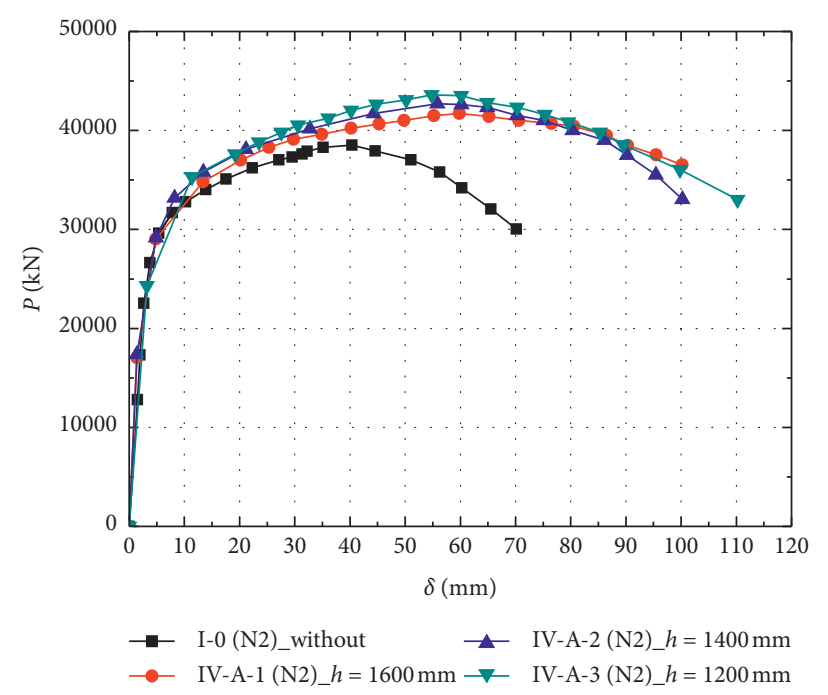

(b)

FigURE 19: Effects of height of LYP steel tubular plate on skeleton curves. (a) Axially compressed specimens. (b) Eccentrically compressed specimens.

\section{Design Formula}

According to the axial compression test and numerical analysis of the new tubular steel piers, type III-B, III-C, and IV-A specimens adopted the structural measures of constrained LYP steel plates, which could improve the mechanical performance of the tubular steel pier. For applying such newly designed tubular steel piers to actual engineering, this paper proposes a formula for calculating the axial bearing ability $N_{\mathrm{u}}$ of such new tubular steel piers, as shown in the following formula:

$$
N_{\mathrm{u}}=C_{1}\left(N_{y}\right)^{C_{2}} \text {. }
$$

In formula (1), $N_{\mathrm{u}}$ is the axial bearing capacity of the new tubular steel pier; $N_{y}$ is the theoretical axial compression load corresponding to the yield of the steel tubular plate; and $N_{y}=f_{y} A$, where $f_{y}$ is the theoretical yield strength of the steel tubular plate and $A$ is the cross-sectional area of the tubular steel pier. Variable $C_{1}$ is a function of the theoretical yield strength $f$ of the LYP steel plate, height $h$ of the LYP steel plate, thickness $t_{\mathrm{w}}$ of the outer constrained steel plate, and thickness $t_{\mathrm{f}}$ of LYP steel tubular plate. Variable $\mathrm{C}_{2}$ is a function of the height $\mathrm{H}$ of the tubular steel pier and the outer diameter $D$ of the tubular steel pier. According to the results of the axial compression test and numerical analysis, 1 stOpt software with optimum modules was used to determine $C_{1}$ and $C_{2}$ parameters. The fitting formula of variables $C_{1}$ and $C_{2}$ in formula (1) is regressed as follows: $\quad C_{1}=\left(-11.193-0.137 f+0.196 h+3.68 t_{\mathrm{w}}+4.786 t_{\mathrm{f}}\right)$, $C_{2}=0.3 H / D$.

By applying formula (1), the ratio $N_{\mathrm{u}} / N_{y}$ can be calculated. This is the ratio between the axial bearing capacity of the new tubular steel pier and the theoretical axial compression load at the yield of the tubular steel plate. The ratio is then compared and analysed with the test and numerical analysis results, as shown in Figure 20. The deviation between the calculation result by formula (1) and

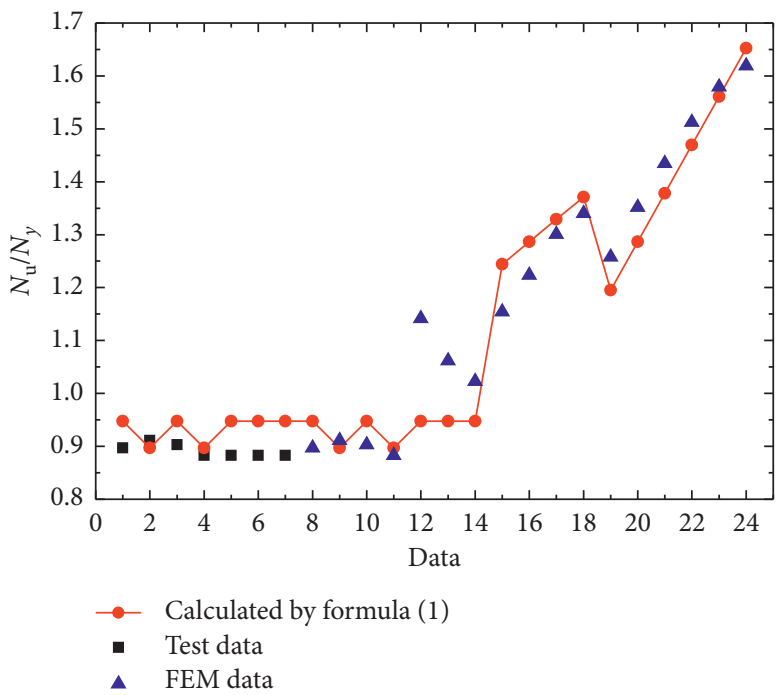

Figure 20: Results by formula (1), axially compressed test, and finite element analysis.

the test data or the numerical result is within $5 \%$, and the maximum deviation is approximately $10 \%$. This indicates that the calculation results by formula (1) in this study agree well with the test data and numerical results. The calculation accuracy of the design formula (1) is high.

\section{Conclusions}

To discuss the effects of different structural details on the mechanical behaviour of the new tubular steel piers designed in this study, an axial compression test and numerical simulation of the newly designed tubular steel piers were performed. The main conclusions are as follows:

(1) The experimental test of the new tubular steel pier demonstrated that the failure mode of the specimens 
could be divided into three categories. (I) Local buckling occurring at the top of the specimen, of which the damage was primarily plastic deformation. (II) Local buckling occurring at the bottom of the specimen, of which the damage was primarily plastic deformation. (III) Concave and convex buckling deformation occurring at the top, middle, and bottom of the specimen, which formed undulating buckling deformation

(2) The deformation ability of the tubular steel pier could not be improved effectively by adding only vertical stiffeners on the steel tubular plate

(3) The T-shaped LYP steel plates and stiffeners on the LYP steel tubular plate should be continuous plates extending the entire specimen to enhance the deformation ability of the tubular steel pier. The thickness $t_{\mathrm{f}}$ of the LYP steel tubular plate should match the thickness $t$ of the common steel tubular plate to effectively improve the deformation capacity of the tubular steel pier. The thickness of the LYP steel tubular plate should satisfy $t \leq t_{\mathrm{f}} \leq 2 t$

(4) For type III-B and III-C specimens with an internally constrained LYP steel plate, the specimens exhibited good plastic deformation ability. The thickness $t_{\mathrm{w}}$ of the outer constrained steel plate should be equal to the thickness $t$ of the common steel tubular plate; that is, $t_{\mathrm{w}}=t$

(5) For type IV-A specimens with LYP steel tubular plates and constrained steel plates on both sides, the mechanical behaviour of the new tubular steel piers improved significantly

(6) Based on the results of experimental data and numerical simulation of the new tubular steel piers, a design formula was proposed to calculate the axial bearing ability of the newly designed tubular steel piers with constrained LYP steel plates.

\section{Data Availability}

The data used to support the findings of this study are included within the article. The experimental data presented in the paper are obtained from the authors. All the test data are available from the corresponding author upon request by email.

\section{Conflicts of Interest}

The authors declare that they have no conflicts of interest regarding the publication of this paper.

\section{Acknowledgments}

This research work was supported by the National Natural Science Foundation of China (no. 51778248), Natural Science Foundation of Fujian Province (no. 2018J01075), Research Trained Fund for Outstanding Young Researcher in Higher Education Institutions of Fujian Province, Natural Science Foundation of Guangdong Province under Grant no. 2018A030310547 (in China), and Subsidized Project for Postgraduates' Innovative Fund in Scientific Research of Huaqiao University (18013086038). Besides, the first author would like to appreciate the China Scholarship Council for sponsoring the visiting at the University of New South Wales under the Grant no. 201807540009. The tests were completed in the Key Laboratory for Structural Engineering and Disaster Prevention of Fujian Province. The support provided by the laboratory staff is gratefully acknowledged.

\section{References}

[1] M. Bruneau, "Performance of steel bridges during the 1995 hyogoken-nanbu (Kobe, Japan) earthquake-a north American perspective," Engineering Structures, vol. 20, no. 12, pp. 1063-1078, 1998.

[2] S. El-Bahey and M. Bruneau, "Bridge piers with structural fuses and Bi-steel columns. I: experimental testing," Journal of Bridge Engineering, vol. 17, no. 1, pp. 25-35, 2012.

[3] S. El-Bahey and M. Bruneau, "Bridge piers with structural fuses and Bi-steel columns. II: analytical investigation," Journal of Bridge Engineering, vol. 17, no. 1, pp. 36-46, 2012.

[4] T. Kitada, M. Matsumura, and Y. Otoguro, "Seismic retrofitting techniques using an energy absorption segment for steel bridge piers," Engineering Structures, vol. 25, no. 5, pp. 621-635, 2003.

[5] S.-J. Chen and J. Chen, "Steel bridge columns with pre-selected plastic zone for seismic resistance," Thin-Walled Structures, vol. 47, no. 1, pp. 31-38, 2009.

[6] K. A. S. Susantha, T. Aoki, T. Kumano, and K. Yamamoto, "Applicability of low-yield-strength steel for ductility improvement of steel bridge piers," Engineering Structures, vol. 27, no. 7, pp. 1064-1073, 2005.

[7] A. Rahmzadeh, M. S. Alam, and R. Tremblay, "Analytical prediction and finite-element simulation of the lateral response of rocking steel bridge piers with energy-dissipating steel bars," Journal of Structural Engineering, vol. 144, no. 11, Article ID 04018210, 2018.

[8] Z.-Q. Jiang, X.-F. Yang, C. Dou, C. Li, and A.-L. Zhang, "Cyclic testing of replaceable damper: earthquake-resilient prefabricated column-flange beam-column joint," Engineering Structures, vol. 183, pp. 922-936, 2019.

[9] Z.-Q. Jiang, C. Dou, A.-L. Zhang, Q. Wang, and Y.-X. Wu, "Experimental study on earthquake-resilient prefabricated cross joints with L-shaped plates," Engineering Structures, vol. 184, pp. 74-84, 2019.

[10] H. Li, J. Luo, F. Han, and J. Luo, "Tests of new box steel replaceable piers under axial compression," International Journal of Steel Structures, vol. 19, no. 3, pp. 896-913, 2019.

[11] H. Li, X. Gao, Y. Liu, and Y. Luo, "Seismic performance of new-type box steel bridge piers with embedded energy-dissipating shell plates under tri-directional seismic coupling action," International Journal of Steel Structures, vol. 17, no. 1, pp. 105-125, 2017.

[12] H. Li, K. Lv, and R. Cui, "Seismic behaviour of eccentrically compressed steel-box bridge-pier columns with embedded energy-dissipating shell plates," Bulletin of Earthquake Engineering, vol. 18, no. 7, pp. 3401-3432, 2020.

[13] T. Ishizawa and M. Iura, "Analysis of tubular steel bridge piers," Earthquake Engineering \& Structural Dynamics, vol. 34, no. 8, pp. 985-1004, 2005.

[14] Q. Al-Kaseasbeh and I. H. P. Mamaghani, "Buckling strength and ductility evaluation of thin-walled steel tubular columns 
with uniform and graded thickness under cyclic loading," Journal of Bridge Engineering, vol. 24, no. 1, Article ID 04018105, 2019.

[15] S. Chen, X. Xie, and H. Zhuge, "Hysteretic model for steel piers considering the local buckling of steel plates," Engineering Structures, vol. 183, pp. 303-318, 2019.

[16] S. Gao, T. Usami, and H. Ge, "Eccentrically loaded steel columns under cyclic out-of-plane loading," Journal of Structural Engineering, vol. 126, no. 8, pp. 974-981, 2000.

[17] S. Gao, T. Usami, and H. Ge, "Ductility evaluation of steel bridge piers with pipe sections," Journal of Engineering Mechanics, vol. 124, no. 3, pp. 260-267, 1998.

[18] T. Usami, Y. Zheng, and H. B. Ge, "Recent research developments in stability and ductility of steel bridge structures," Journal of Constructional Steel Research, vol. 55, no. 1-3, pp. 183-209, 2000.

[19] Z. Wang and Y. Toshitaka, "Ultimate strength and ductility of stiffened steel tubular bridge piers," International Journal of Steel Structures, vol. 11, no. 1, pp. 81-90, 2011.

[20] D. Li, L. Jin, X. Du, J. Fu, and A. Lu, "Size effect tests of normal-strength and high-strength RC columns subjected to axial compressive loading," Engineering Structures, vol. 109, pp. 43-60, 2016.

[21] F.-C. Wang, H.-Y. Zhao, and L.-H. Han, "Analytical behavior of concrete-filled aluminum tubular stub columns under axial compression," Thin-Walled Structures, vol. 140, pp. 21-30, 2019.

[22] F. Aslani, B. Uy, J. Hur, and P. Carino, "Behaviour and design of hollow and concrete-filled spiral welded steel tube columns subjected to axial compression," Journal of Constructional Steel Research, vol. 128, pp. 261-288, 2017.

[23] Z.-B. Wang, Z. Tao, L.-H. Han, B. Uy, D. Lam, and W.-H. Kang, "Strength, stiffness and ductility of concretefilled steel columns under axial compression," Engineering Structures, vol. 135, pp. 209-221, 2017.

[24] Y. L. Li, X. L. Zhao, and R. K. S. Raman, "Theoretical model for concrete-filled stainless steel circular stub columns under axial compression," Journal of Constructional Steel Research, vol. 157, pp. 426-439, 2019.

[25] W. Li and Y.-X. Cai, "Performance of CFDST stub columns using high-strength steel subjected to axial compression," Thin-Walled Structures, vol. 141, pp. 411-422, 2019.

[26] Y. Zheng and Z. Tao, "Compressive strength and stiffness of concrete-filled double-tube columns," Thin-Walled Structures, vol. 134, pp. 174-188, 2019.

[27] F.-Y. Liao, C. Hou, W.-J. Zhang, and J. Ren, "Experimental investigation on sea sand concrete-filled stainless steel tubular stub columns," Journal of Constructional Steel Research, vol. 155, pp. 46-61, 2019.

[28] Y. Huang, J. Fu, D. Wu, A. Liu, W. Gao, and Y. Pi, "Dynamic stability of slender concrete-filled steel tubular columns with general supports," International Journal of Structural Stability and Dynamics, vol. 19, no. 4, Article ID 1950045, 2019.

[29] B. Yan, X. Zhou, and J. Liu, "Behavior of circular tubed steelreinforced-concrete slender columns under eccentric compression," Journal of Constructional Steel Research, vol. 155, pp. 342-354, 2019.

[30] M. Wei, K. Lin, and H. Liu, "Experimental investigation on hysteretic behavior of a shear thickening fluid damper," Structural Control and Health Monitoring, vol. 26, no. 9, Article ID e2389, 2019.

[31] G. Shi, X. Jiang, W. Zhou, T.-M. Chan, and Y. Zhang, "Experimental study on column buckling of $420 \mathrm{MPa}$ high strength steel welded circular tubes," Journal of Constructional Steel Research, vol. 100, pp. 71-81, 2014.

[32] Z. Xiong, Q. Cai, F. Liu, L. Li, and Y. Long, "Dynamic performance of RAC-filled double-skin tubular columns subjected to cyclic axial compression," Construction and Building Materials, vol. 248, Article ID 118665, 2020.

[33] K. He and Y. Chen, "Experimental evaluation of built-in channel steel concrete-filled GFRP tubular stub columns under axial compression," Composite Structures, vol. 219, pp. 51-68, 2019.

[34] K. He, Y. Chen, and S. Han, "Experimental investigation of square stainless steel tubular stub columns after elevated temperatures," Journal of Constructional Steel Research, vol. 159, pp. 397-414, 2019.

[35] X. Zhou, W. Wang, K. Song, and Y. F. Chen, "Fire resistance studies on circular tubed steel reinforced concrete stub columns subjected to axial compression," Journal of Constructional Steel Research, vol. 159, pp. 231-244, 2019.

[36] J. Deng, T. H. Liu, W. Z. Xie, and W. Lu, "Study on repaired earthquake-damaged bridge piers under seismic load," Advances in Materials Science and Engineering, vol. 2015, Article ID 295392, p. 10, 2015.

[37] B. Zhang, G.-S. Feng, Y.-L. Wang, C.-C. Lai, C.-C. Wang, and X.-M. Hu, "Elliptical FRP-concrete-steel double-skin tubular columns under monotonic axial compression," Advances in Materials Science and Engineering, vol. 2020, Article ID 7573848, 16 pages, 2020.

[38] GB/T28905, Low Yield Strength Plates for Construction, China Quality and Standards Publishing \& Media Co., Ltd., Beijing, China, 2012. 